ACCEPTED MANUSCRIPT

\title{
Zn- and (Mn, Zn)-substituted $<i>$ versus $<$ i $>$ unsubstituted magnetite nanoparticles: Structural, magnetic and hyperthermic properties
}

To cite this article before publication: Nataša Jovi Orsini et al 2020 Nanotechnology in press https://doi.org/10.1088/1361-6528/ab76e7

\section{Manuscript version: Accepted Manuscript}

Accepted Manuscript is "the version of the article accepted for publication including all changes made as a result of the peer review process, and which may also include the addition to the article by IOP Publishing of a header, an article ID, a cover sheet and/or an 'Accepted Manuscript' watermark, but excluding any other editing, typesetting or other changes made by IOP Publishing and/or its licensors"

This Accepted Manuscript is @ 2020 IOP Publishing Ltd.

During the embargo period (the 12 month period from the publication of the Version of Record of this article), the Accepted Manuscript is fully protected by copyright and cannot be reused or reposted elsewhere.

As the Version of Record of this article is going to be / has been published on a subscription basis, this Accepted Manuscript is available for reuse under a CC BY-NC-ND 3.0 licence after the 12 month embargo period.

After the embargo period, everyone is permitted to use copy and redistribute this article for non-commercial purposes only, provided that they adhere to all the terms of the licence https://creativecommons.org/licences/by-nc-nd/3.0

Although reasonable endeavours have been taken to obtain all necessary permissions from third parties to include their copyrighted content within this article, their full citation and copyright line may not be present in this Accepted Manuscript version. Before using any content from this article, please refer to the Version of Record on IOPscience once published for full citation and copyright details, as permissions will likely be required. All third party content is fully copyright protected, unless specifically stated otherwise in the figure caption in the Version of Record.

View the article online for updates and enhancements. 


\title{
Zn- and (Mn, Zn)-substituted versus unsubstituted magnetite nanoparticles: Structural, magnetic and hyperthermic properties
}

\author{
N. Jovil Orsini ${ }^{*}$, M. M. Milil ${ }^{1}$ and T. E. Torres ${ }^{2}$ \\ ${ }^{1}$ Institute of Nuclear Sciences òVinl aò, Laboratory of Theoretical Physics and Condensed Matter \\ Physics (020), University of Belgrade, P.O. Box 522, RS-11001 Belgrade, Serbia \\ ${ }^{2}$ Instituto de Nanociencia de Aragón and Departamento de Fisica de la Materia Condensada, \\ Universidad de Zaragoza, Mariano Esquillor s/n 500018, Zaragoza, Spain
}

*Corresponding Author:

Dr. Natağa Joviĺ Orsini

ORCID iD: https://orcid.org/0000-0003-1613-3361

E-mail:natasaj@vin.bg.ac.rs

\section{Abstract}

In this work, we studied structural and magnetic properties of 18nm-sized Zn-substituted magnetite, 28nm-sized unsubstituted and 17nm-sized (Mn,Zn)-substituted iron oxide nanoparticles, synthesized by thermal decomposition method. Their features were examined by analyzing the X-ray diffraction (XRD) data, ${ }^{57} \mathrm{Fe}$ Mössbauer spectra and magnetization measurements by SQUID interferometer. The microstructure was inspected comparing different the size and strain broadening models incorporated into Fullprof software. In terms of crystallinity and size dispersion, applied synthesis protocol shows superiority over decomposition of iron oleate and the co-precipitation synthesis route. The saturation magnetization at $\mathrm{T}=5 \mathrm{~K}$ was found to be within the $M_{\mathrm{S}}=91.2-98.6 \mathrm{Am}^{2} / \mathrm{kg}$ range, while at $300 \mathrm{~K}$ $M_{\mathrm{S}}$ of pure and $\mathrm{Zn}$-substituted $\mathrm{Fe}_{3} \mathrm{O}_{4}$ nanoparticles is 83.6 and $86.2 \mathrm{Am} / \mathrm{kg}$, respectively. Effective magnetic anisotropy constant $K_{\text {eff }}$, estimated under slow measurements by SQUID, is below $20 \mathrm{~kJ} / \mathrm{m}^{3}$ in all three samples. Some preliminary measurements of the magnetic hyperthermia performance, expressed via Specific Absorption Rate $(S A R)$ value showed that the best heating performances were displayed by $18 \mathrm{~nm}$-sized oleic acid-coated $\mathrm{Zn}_{0.13} \mathrm{Fe}_{2.87} \mathrm{O}_{4}$ cubooctahedrons with $S A R \cong 425 \mathrm{~W} / \mathrm{g}_{\mathrm{Fe}}$ at $H_{0}=20 \mathrm{kA} / \mathrm{m}$ and $f=228 \mathrm{kHz}$. 
Keywords: magnetite-based nanoparticles, Mössbauer spectroscopy, magnetic hyperthermia, microstructure

\section{INTRODUCTION}

Magnetite $\left(\mathrm{Fe}_{3} \mathrm{O}_{4}\right)$ and a series of mixed spinel ferrites $\left(\mathrm{MO} \cdot \mathrm{Fe}_{2} \mathrm{O}_{3}, \mathrm{M}\right.$ being the divalent transition metal cations) have been of a technological and scientific interest for a long time. Their nanoparticulate forms have been exploited in medicine and new technologies in the last decades [1-4]. Due to the satisfied biocompatibility and biodegradability, ferrofluids based on superparamagnetic iron oxide-based nanoparticles (IONPs) have high potential for applications in medical diagnostic and curing procedures, particularly as contrast media for biomedical imaging (magnetic particle (MPI) or resonance (MRI) imaging) [5, 6] as magnetically-driven drug/gene delivery systems [7] or magnetic thermoseeds for magnetic particle hyperthermia (MPH) treatment of ill tissues [7-12]. Other iron oxide-based nanostructures, such as dumbbell, porous, core/shell, hollow or hybrid ones, have been also investigated for biomedical applications [13].

The applicability of the magnetic nanoparticles in biomedicine is closely related to their own characteristics such as magnetic and microstructural features (e.g. size and shape, surface chemistry, composition, degree of crystallinity). Another important item, which should be considered regarding their bio-applicability is the way how MNPs interact with cells. The magnetic properties of nanoparticles are usually altered in in vivo conditions due to the unavoidable nanoparticle's clustering and movement restriction after interaction with cells [14]. Consequently, their biomedical performances are changed.

One of the promising application of superparamagnetic IONPs is their use for magnetic hyperthermia therapy [7-12]. Under exposure to an alternating magnetic field, superparamagnetic IONPs suspended in a fluid can absorb energy from the applied AC magnetic field and release it as heat. If they are properly functionalized and located in ill tissues, they will be able to inhibit activity of cancer cells by locally increasing temperature [7, 12]. To improve the heating efficiency, IONPs should possess the optimal size and shape, narrow size distribution and enhanced magnetic performances (e.g. high $M_{\mathrm{S}}$ and $K_{\text {eff }}$ value). In recent years, remarkable 
achievements in tailoring the optimal size and shape of nanoparticles have been accomplished [9, $10,15,16]$. Once that the particle size close to the critical value (related to the transition from superparamagnetic to ferrimagnetic regime) is reached, further increase of the heating efficiency can be achieved by changing the composition of IONPs from pure $\left(\mathrm{Fe}_{3} \mathrm{O}_{4}\right)$ toward substitutedmagnetite $\left(\mathrm{Fe}_{3-\mathrm{x}} \mathrm{M}_{\mathrm{x}} \mathrm{O}_{4}\right)$ nanoparticles [1, 5, 17]. It was shown that $\mathrm{Zn}$-substituted $\mathrm{Fe}_{3} \mathrm{O}_{4}$ nanoparticles represent one of the best choices, due to the low toxicity of $\mathrm{Zn}$ ions and the positive impact of $\mathrm{Zn}$-ion substitution on the magnetic saturation value. Magnetite is a typical inverse spinel with one half of $\mathrm{Fe}^{3+}$ ions in tetrahedral (A) sites, and the second half of $\mathrm{Fe}^{3+}$ and all $\mathrm{Fe}^{2+}$ ions in octahedral (B) sites. The effect of magnetic $\mathrm{Fe}^{3+}$ ions substitution by diamagnetic $\mathrm{Zn}^{2+}$ ones at the tetrahedral, A-sites of the spinel lattice (represented by the formula $\mathrm{AB}_{2} \mathrm{O}_{4}$ (S.G. $F d \overline{3} m)$ ), is well known and visible by increases of the saturation magnetization, $M_{\mathrm{S}}$, for doping level up to $x \approx 0.4$ [18]. Relating to hyperthermia or magnetic sensing potential, superiority of cubic over spherical nanoparticles has been revealed, as well as of $\mathrm{Zn}$-doped over pure $\mathrm{Fe}_{3} \mathrm{O}_{4}$ nanoparticles $[6,19,20]$. Recently, it has been revealed that silica-coated nonstoichiometric Gd$\mathrm{Zn}$ ferrite exhibits the most promising therapeutic capability at relatively low particle concentrations [8]. Further improvement in the heating performances has been observed when $\mathrm{Fe}_{3} \mathrm{O}_{4}$ nanoparticles change shape and move from 3-dim objects (spherical and cubic) to 1-dim objects (nanorods) [15]. In terms of interparticle interactions, Tong et al., reported that well dispersed $33 \mathrm{~nm}$ sized ferromagnetic iron oxide nanocrystals heat much better than their aggregates [9].

Along with magnetic properties, the microstructure of nanoparticles is important item in defining the nanoparticleố biomedical performances [21-25]. For that reason, a closer relation between the degrees of the nanoparticles crystallinity, phase composition and the magnetic response should be established. It could give better insight into understanding of hyperthermia efficiency of magnetic nanoparticles.

In this paper, we report on the structural, magnetic and hyperthermic characteristics of three samples, composed of unsubstituted, $\mathrm{Zn}$ - and (Mn,Zn)-substituted $\mathrm{Fe}_{3} \mathrm{O}_{4}$ nanoparticles, synthesized by thermal decomposition method. We discuss the main advantages of this method (e.g. production of well crystallized nanoparticles with narrow size distribution) keeping in mind all shortcomings (use of expensive and environmentally harmful substances, need of a postsynthesis treatment to transfer nanoparticles into water, etc.). The degree of crystallinity and 
microstrains in the samples were evaluated from refinement of the XRD data using the Fullprof program. Different combinations of the size and strain broadening models were tested (isotropic vs. anisotropic), and the comparative analysis was done. Magnetic characterization of the powdered samples was performed using the Mössbauer spectroscopy and measurements by SQUID. Some preliminary measurements of the magnetic hyperthermia performance (expressed via the $S A R$ value), were carried out on ferrofluids made of oleic acid-coated $\mathrm{Fe}_{3} \mathrm{O}_{4}$ nanoparticles (pure and substituted), dispersed in hexane, under physiologically tolerable AC magnetic field conditions.

\section{MATERIALS AND METHODS}

\subsection{Chemicals}

Iron(III) acetylacetonate $\left(\mathrm{Fe}(\mathrm{acac})_{3}, \geq 99.9 \%\right.$ p.a. Sigma Aldrich), zinc(II) acetylacetonate hydrate $\left(\mathrm{Zn}(\mathrm{acac})_{2} \cdot\right.$ hydrate, Aldrich), zinc(II) chloride $\left(\mathrm{ZnCl}_{2}, \geq 97 \%\right.$, Sigma Aldrich), iron(II) chloride tetrahydrate $\left(\mathrm{FeCl}_{2} \cdot 4 \mathrm{H}_{2} \mathrm{O}, \geq 99.0 \%\right.$ p.a. Sigma Aldrich), benzyl ether (98\%, Aldrich), oleic acid (techical grade, >90\%, Aldrich), oleylamine (techical grade, $>70 \%$, Aldrich).

\subsection{Synthesis of magnetite-based cuboctahedral nanoparticles}

Unsubstituted and Zn- and (Mn, Zn)-substituted magnetite nanoparticles were synthesized by thermal decomposition of metal precursors (acetylacetonate and chloride salts), in benzyl ether, under bubbling of nitrogen, in the presence of oleic acid and oleylamine as surfactants. Not any reducing agent was used. The concentration of metal cations was kept constant at 0.1 mol per $\mathrm{dm}^{3}$ of solvent. The molar ratios of the used reactants, given in the table 1, were set up according to the desired compositions of the products: $\mathrm{Zn}_{0.4} \mathrm{Fe}_{2.6} \mathrm{O}_{4}$, in samples $\mathbf{1}$ and $\mathbf{2}$, and $\mathrm{Mn}_{0.5} \mathrm{Zn}_{0.5} \mathrm{Fe}_{2} \mathrm{O}_{4}$ in sample 3. Due to the fact that incorporation of $\mathrm{Zn}^{2+}$ ions into a spinel structure is difficult to achieve when this synthesis route is chosen, two different sources of $\mathrm{Zn}^{2+}$ ions were used, $\mathrm{Zn}(\mathrm{acac})_{2}$ (sample 1) or $\mathrm{ZnCl}_{2}$ salt (samples $\mathbf{2}$ and 3). In the sample 2, the $\mathrm{FeCl}_{2} \cdot 4 \mathrm{H}_{2} \mathrm{O}$ precursor was used as a source of $\mathrm{Fe}^{2+}$ ions. 

$\mathrm{mL}$ of benzyl ether.

\begin{tabular}{|l|l|l|l|l|l|l|l|l|}
\hline Sample & $\begin{array}{l}\mathbf{Z n}_{(\text {acac })_{2}} \\
\text { hydrate } \\
(\mathbf{m m o l})\end{array}$ & $\mathbf{F e}(\mathbf{a c a c})_{3}$ & $\begin{array}{l}\mathbf{M n C l}_{2} \cdot \\
\mathbf{4} \mathbf{H}_{\mathbf{2}} \mathbf{O} \\
(\mathbf{m m o l})\end{array}$ & $\mathbf{Z n C l}_{2}$ & $\begin{array}{l}\mathbf{F e C l}_{2} \cdot \\
\mathbf{4} \mathbf{H}_{\mathbf{2}} \mathbf{O} \\
(\mathbf{m m o l})\end{array}$ & $\mathbf{O A}$ & $\mathbf{O M}$ & $\begin{array}{l}\text { Actual } \\
\text { stoichiometry } \\
(\mathbf{m m o l})\end{array}$ \\
\hline $\mathbf{1 - Z 1 8}$ & 0.8 & 5.2 & - & - & - & 24 & - & $\begin{array}{l}(\mathbf{m m o l}) \\
(\mathbf{E D X})\end{array}$ \\
\hline $\mathbf{2 - F 2 8}$ & - & 4 & - & 0.8 & 1.2 & 18 & 18 & $\mathrm{Zn}_{0.13} \mathrm{Fe}_{2.87} \mathrm{O}_{4}$ \\
\hline 3-MZ17 & - & 4 & 1 & 1 & - & 18 & 18 & $\mathrm{Fe}_{3} \mathrm{O}_{4}$ \\
\hline
\end{tabular}

In a typical procedure, the $\mathrm{Zn}$-containing sample 1 (i.e. Z18)/was synthesized starting from a mixture of $\mathrm{Zn}(\mathrm{acac})_{2}$.hydrate $(0.8 \mathrm{mmol}), \mathrm{Fe}(\mathrm{acac})_{3}(5.2 \mathrm{mmol})$, oleic acid (24 mmol), and $60 \mathrm{~mL}$ of benzyl ether (the cations-to-OA molar ratio was kept at 1:4). The mixture was poured in a three neck flask ( $250 \mathrm{~mL}$ volume) and mechanically stirred at room temperature for 30 minutes under nitrogen flow. The heating started, first up to $200{ }^{\circ} \mathrm{C}$, followed by aging for $\sim 2$ hours at that temperature, and then up to the boiling temperature of the mixture $\left(\sim 290{ }^{\circ} \mathrm{C}\right)$ under refluxing conditions (see figure S1). A heating rate to reflux was around $8{ }^{\circ} \mathrm{C} / \mathrm{min}$, and the reaction time was about one hour. Afterwards, the flask was removed from a heating mantle and the product of reaction was left to cool down to room temperature. The black precipitate was magnetically collected, washed two or three times in an excess of ethanol and hexane, and redispersed in hexane. Similarly, the synthesis of samples $\mathbf{2}$ and $\mathbf{3}$ were carried out starting from the mixture of reactants listed in table 1. But, for preparation of these two samples $\mathrm{ZnCl}_{2}$ salt was used as a precursor of $\mathrm{Zn}^{2+}$ ions and, in addition to oleic acid, oleylamine was used, too (the cations-to-OA-to-OM molar ratio was 1:3:3). The heating rates $(\partial \mathrm{T} / \partial \mathrm{t})$, the aging time, $t_{\text {aging }}(2$ hours at the ramp and 1 hour under refluxing), and the reaction temperatures $\left(\mathrm{T}_{\mathrm{r}} \sim 290-270{ }^{\circ} \mathrm{C}\right)$ were kept almost the same in all three synthesis.

\subsection{Characterization}

Morphology, structure, microstructure and composition of the samples were analyzed by Transmission Electron Microscopy (TEM), X-ray diffraction (XRD) and Energy-Dispersion Xray (EDX) spectroscopy. Magnetic properties were studied from ${ }^{57} \mathrm{Fe}$ Mössbauer spectra analysis and the temperature and field dependence of magnetization (measured by SQUID). The 
powdered specimens of the prepared samples, used for characterization, were obtained after precipitation of nanocrystals from hexane upon adding ethanol and drying under nitrogen flow.

TEM (FEI TECNAI T20, $200 \mathrm{kV}$ ) and HRTEM (FEI TECNAI T30, $300 \mathrm{kV}$ ) microscopes were used to examine the nanoparticles morphology, average size and size distribution. Nanoparticle specimens for TEM were prepared by placing a drop of a diluted solution (in hexane) onto a carbon-coated cupper grid. Images were analyzed using the DigitalMicrograph program. To estimate the average particle size from TEM, between 200 and 400 nanoparticles were counted. Electron microprobe analyses were obtained using a scanning electron microscope (SEM) connected with an energy-dispersion X-ray analysis (EDX) unit.

XRD patterns of all three samples were collected using Rigaku SmartLab diffractometer and $\mathrm{Cu} K \alpha$ and $K \beta$ radiation. The XRD data were collected in a $2 \theta$ range between 10 and 90 or $100^{\circ}$, with the step-size of $0.02^{\circ}$, and a speed counting rate of $0.2 \%$. The collected data were fitted using the program Fullprof based on the Rietveld method. Both, structural and microstructural parameters were refined for all samples in the space group $F d \overline{3} m$ (No.227), assuming a spinel structure. XRD peak profiles were modeled by the Thomson-Cox-Hasting modified pseudo-Voigt (TCH-pV) function. A correction for instrumental broadening was done considering the experimental profile as a convolution of the instrumental profile and the specimen profile. The instrumental resolution function (IRF) was obtained upon refinement of the standard, lanthanum hexaboride $\left(\mathrm{LaB}_{6}\right)$. Following structural parameters: lattice constant, $a$, fractional coordinates for oxygen in $32 e$ site and isotropic displacement parameters, $B$, as well as microstructural parameters: the average crystallite size, $d_{\mathrm{XRD}}$, and microstrain, were fitted. The background was refined úsing linear interpolation between selected points.

Magnetic properties of the samples were studied using the Mössbauer spectroscopy and measurements of the magnetization by MPMS XL-5 SQUID magnetometer. The Mössbauer spectra of samples were collected at room temperature, in transmission geometry using a ${ }^{57} \mathrm{Co} \gamma$ ray source within a Rh matrix. The velocity scale was calibrated relative to standard $\alpha$-Fe foil. The best fit of the spectra was achieved considering a distribution of magnetic sextets through Voigt-based profile analysis ( $\chi^{2}$ close to one). Field-cooled (FC) and zero-field-cooled (ZFC) DC magnetization measurements were performed in a magnetic field of $7.96 \mathrm{kA} / \mathrm{m}(100 \mathrm{Oe})$, in the $5-300 \mathrm{~K}$ temperature range, following standard protocol. Hysteresis loops, $M(\mathrm{H})$, were recorded at 5 and $300 \mathrm{~K}$ at magnetic field up to $3978.88 \mathrm{kA} / \mathrm{m}(50 \mathrm{kOe})$. To calculate the mass 
magnetization accurately, the thermogravimetric analysis (TGA) and the differential thermal analysis (DTA) were employed using a TA SDT 2960 instrument. TGA/DTA analysis was performed in air, at a heating rate of $10{ }^{\circ} \mathrm{C} / \mathrm{min}$, up to $700{ }^{\circ} \mathrm{C}$. The weight loss due to evaporation of organic phase (in wt\%), obtained by the TGA/DTA analysis, was re-calculated taking into account that during heating the partial oxidation takes place, bringing in a mixture of hematite and magnetite phases (proved by the XRD analysis of thermally treated samples; not shown).

Preliminary measurements of the heating efficiency of here investigated ferrofluids composed of iron oxide-based nanoparticles $(\mathbf{1}, \mathbf{2}$, and $\mathbf{3})$ dispersed in hexane, were done using a calorimetric analyzer (DM 100 Series, by nBnanoScale Biomagnetics, Spain). The specific absorption rate $(S A R)$ of all samples was determined from the measurement of the temperature rise in time, $T(\mathrm{t})$, when the ferrofluids (previously placed in a $2 \mathrm{ml}$ glass holder) were exposed to an alternating magnetic field, $H=H_{0} \sin (\omega \mathrm{t})\left(H_{0}\right.$ - is the magnetic field amplitude, and $\omega$ - is an angular velocity) [7]. The $T(\mathrm{t})$ curves were recorded using an optical fiber temperature probe immersed inside the ferrofluids. During the measurements, a glass holder with ferrofluids $\mathbf{1}$ and $\mathbf{2}$ was placed in a high-vacuum environment allowing us to consider almost adiabatic conditions of SAR measurements. The $T(\mathrm{t})$ curves for ferrofluid $\mathbf{3}$ were recorded five months later under slightly different conditions (frequency was $252 \mathrm{kHz}$ (instead of $228 \mathrm{kHz}$ ) and without vacuum isolation). The following expression was used to estimate $S A R$ value: $S A R\left(\mathrm{~W} / \mathrm{g}_{\mathrm{Fe}}\right) \cong \rho_{\text {hexane }} \times$ $\mathrm{c}_{\text {hexane }} \times(\Delta \mathrm{T} / \Delta \mathrm{t})_{\max } \times\left[x_{\mathrm{Fe}}\right]^{-1}$, where $\rho_{\text {hexane }}=654.8 \mathrm{~kg} / \mathrm{m}^{3}$ is the density and $\mathrm{c}_{\text {hexane }}=2.26 \mathrm{~J} / \mathrm{g}{ }^{\circ} \mathrm{C}$ is the specific heat capacity of hexane, $(\Delta \mathrm{T} / \Delta \mathrm{t})_{\max }$ is the initial slope of the heating curve $T(\mathrm{t})$ and $\left[x_{\mathrm{Fe}}\right]$ is the average concentration of $\mathrm{Fe}^{3+}$ ions in ferrofluids. The $\left[x_{\mathrm{Fe}}\right]$ was determined comparing the UV-vis absorbance of $\mathrm{Fe}^{3+}$ ions from sample solutions (after oxidation) with the calibration curve obtained measuring the UV-absorbance of patron solutions of known, but different $\mathrm{Fe}^{3+}$ concentrations [26]. Patron solutions were prepared from iron standard solution (in a mixture of $6 \mathrm{M} \mathrm{H}_{2} \mathrm{SO}_{4}$ and $65 \% \mathrm{HNO}_{3}$ ). The absorbance was measured by $\mathrm{UV}$-visible spectrometer when solution was exposed to irradiation $(\lambda=480 \mathrm{~nm})$.

\subsection{Rietveld refinement}

The structural and microstructural parameters of Zn-doped (sample 1), unsubstituted (sample 2), and $(\mathrm{Mn}, \mathrm{Zn}$ )-containing (sample 3) magnetite, were refined in a model in which the stoichiometry of the samples was adjusted according to the results obtained by EDX analysis 
(see figure S2). The cations distribution was modeled in accordance with the preferred cations occupancy and not refined. Such an assumption is reliable since, for X-rays, ions with low electron density difference do not distinguish significantly. In the $\mathrm{Zn}$ - and (Mn, Zn)-containing magnetite all zinc cations occupy tetrahedrally coordinated, $8 a$ sites (A-sites). Although in nanostructured $\mathrm{Zn}$-doped magnetite $\left(\mathrm{Zn}_{\mathrm{x}} \mathrm{Fe}_{3-\mathrm{x}} \mathrm{O}_{4}\right)$, the $\mathrm{Zn}^{2+}$ ions can occupy both $\mathrm{A}$ and $\mathrm{B}$ sites, for $x<0.4$, the $\mathrm{Zn}^{2+}$ ions follow their high preference for tetrahedral A-sites, valid for bulk materials $[5,18]$. In addition, cations distribution in the ( $\mathrm{Mn}, \mathrm{Zn})$-doped sample was previously set up in the way so that all manganese ions were considered to be +2 valence and in A-sites, even though it is known that the manganese ions can easily vary the yalence state (between $+2 /+3$ ), and that $\mathrm{Mn}^{3+}$ ions preferably occupy octahedral, B-sites (16d)/[27]. After refinement of the Mössbauer spectra, the presence of $\mathrm{Mn}^{3+}$ ions in B-sites was allowed. The attempt to refine occupation parameters of cations and to determined the cations distribution failed due to the fact that the zinc $\left(3 d^{10} 4 s^{2}\right)$ and iron $\left(3 d^{6} 4 s^{2}\right)$ are the fourth, while manganese $\left(3 d^{5} 4 s^{2}\right)$ and iron are the nearest neighbours in the periodic system. As such, they are hardly distinguished for X-rays. In addition, refinement of the crystal structure solely, when pseudo-Voigt function was used to delineate diffraction profiles and the instrumental broadening was disregarded, gave very good agreement between experimental and refined XRD patterns, regardless the cations distribution over the $8 a$ and $16 d$ sites.

When the microstructural analysis was applied, the XRD peak profiles were modeled by the TCH-pV function and the IRF function was included (see section 2.3). Different combinations of the isotropic/anisotropic size and strain broadening were considered during refinement. An anisotropic size broadening was considered as a linear combination of spherical harmonics (SPH) [28]. In the case of an anisotropic strain broadening, the Stephens parameters, $S_{400}$ and $S_{220}$, for $m 3 m$ symmetry, were refined [28, 29].

\section{RESULTS AND DISCUSSION}

\subsection{Composition, morphology and size}

The experimental XRD patterns of all three samples, $\mathbf{1 ,} \mathbf{2}$ and 3, are shown in the figure S3 (see Supplementary Info). All reflections were indexed in a spinel structure with cubic symmetry (space group $F d-3 m$, No. 227). The reflection at $2 \theta \sim 32^{\circ}$ with very low intensity (observed in all 
three XRD patterns), is a satellite of the major (311) spinel reflection caused by $\mathrm{Cu} K \beta$ radiation of wavelength $1.39217 \AA$. It might be accidentally ascribed to the (100) reflection of $\mathrm{ZnO}$ phase. Since, no improvement in the crystal structure refinement was observed in a two phases model, $\mathrm{ZnO}$ phase presence was ruled out. The presence of hematite or $\mathrm{FeO}$ as an impurity was excluded in all three samples due to the results of Mössbauer spectra analysis (see forthcoming results).

The EDX analysis on selected surfaces of the studied samples showed that the amount of incorporated $\mathrm{Zn}$ and $\mathrm{Mn}$ ions into the spinel structure is notably lower than it was set up by the initial stoichiometry of precursors (table 1). According to it, the sample $\mathbf{1}$ is $\mathrm{Zn}$-doped, the sample $\mathbf{2}$ is unsubstituted, while the sample $\mathbf{3}$ is $(\mathrm{Mn}, \mathrm{Zn})$-containing magnetite, with the stoichiometry $\mathrm{Zn}_{0.13} \mathrm{Fe}_{2.87} \mathrm{O}_{4}, \mathrm{Fe}_{3} \mathrm{O}_{4}$ and $\mathrm{Mn}_{0.06} \mathrm{Zn}_{0.04} \mathrm{Fe}_{2.9} \mathrm{O}_{4}$, respectively.

TEM images of the samples $\mathbf{1}, \mathbf{2}$ and $\mathbf{3}$, and their size distributions are shown in figure 1. The highest uniformity of particles size and shape is achieved in the sample 1. It is evident that most of the nanoparticles are cubo-octahedra-like in shape. Nanoparticles with shapes different than those are observed in the samples $\mathbf{2}$ and $\mathbf{3}$, but significantly less in number. Average edge dimensions of the nanoparticles, obtained by fitting the size distribution with Gauss function, were found to be 18.3, 28.1 and $17.2 \mathrm{~nm}$ for $\mathbf{1}, \mathbf{2}$ and 3, respectively. According to the results of EDX and TEM analysis we re-label the samples as: $\mathbf{1}$ is Z18, 2 is F28 and 3 is MZ17, where the capital latter indicate composition, while the number indicates the average particle size.

For the sake of comparison, $\mathrm{Zn}$-substituted $\mathrm{Fe}_{3} \mathrm{O}_{4}$ nanoparticles were synthesized following the classical thermal decomposition synthesis (when 1,2-hexadecanediol was used as a reducing agent). Thus obtained nanoparticles are quasi-spherical with an average diameter $\sim 10$ $\mathrm{nm}$ (figure S4). Based on the literature data, the polyalcohol, when acting as a reducing agent, can produce polyaldehydes and polyorganic acids, whose presence during the synthesis can suppress formation of bigger nanoparticles [30]. Thus, partial reducing or avoiding adding of polyalcohol in the synthesis seems to be the easiest way to obtain bigger nanoparticles. In addition, by fine tuning of the cations/capping ligands molar ratio and the heating rate to reflux, it is possible to further manipulate the size and shape of nanoparticles [16]. Such an approach in the thermal decomposition of metal precursors becomes competitive to the co-precipitation synthesis route $[22,23]$, the two steps synthesis via decomposition of iron oleate complexes [31, 
32], or polyol method [33], in the sense of designing bigger nanoparticles with high degree of crystallinity and low density of defects.
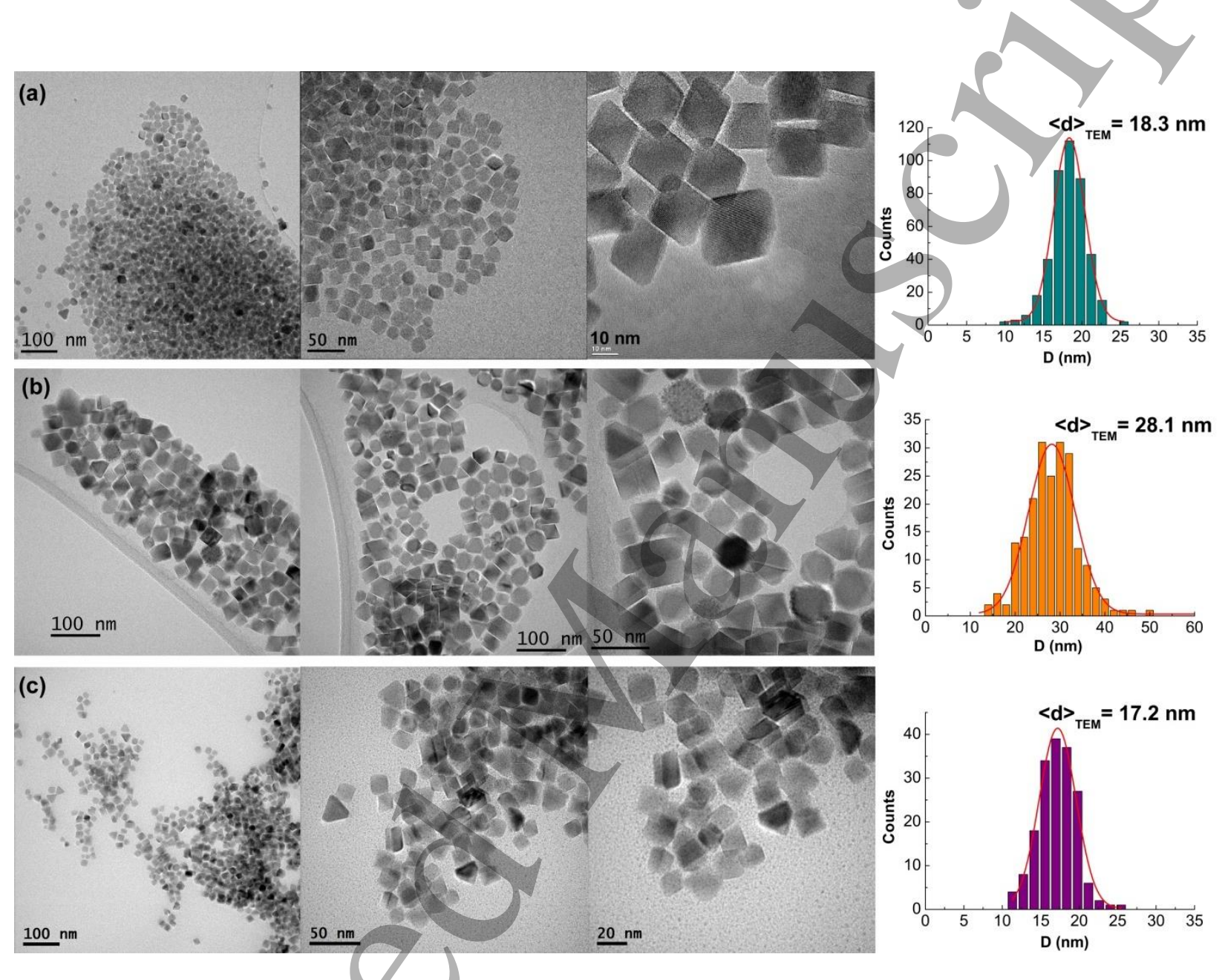

Figure 1. TEM images of the samples: (a) 1-Z18, (b) 2-F28 and (c) 3-MZ17, with the stoichiometry $\mathrm{Zn}_{0.13} \mathrm{Fe}_{2.87} \mathrm{O}_{4}, \mathrm{Fe}_{3} \mathrm{O}_{4}$ and $\mathrm{Mn}_{0.06} \mathrm{Zn}_{0.04} \mathrm{Fe}_{2.9} \mathrm{O}_{4}$, respectively.

Following the above mentioned modification in the synthesis procedure, it seems that $\mathrm{Zn}^{2+}$ ions are built in into the spinel structure more efficiently when $\mathrm{Zn}(\mathrm{acac})_{2}$ salt is used (sample 1), instead of $\mathrm{ZnCl}_{2}$ precursor (samples 2 and 3). Generally, building-in $\mathrm{Zn}$ ions into the spinel structure is difficult and dependent on the used precursors for $\mathrm{Zn}$ ions [5, 17, 34, 35]. The large difference in the decomposition temperature between $\mathrm{Zn}(\mathrm{acac})_{2}\left(\mathrm{~T}_{\mathrm{dec}} \approx 248{ }^{\circ} \mathrm{C}\right)$ and $\mathrm{Fe}(\mathrm{acac})_{3}\left(\mathrm{~T}_{\mathrm{dec}} \approx 180^{\circ} \mathrm{C}\right)$ salts of almost $70{ }^{\circ} \mathrm{C}$, obviously impedes the incorporation of zinc ions 
into the spinel crystal structure $[34,35]$. It might be also that presence of water, introduced as bounded molecules to chloride salts (in samples 2-F27 and 3- MZ17), has negative impact on this process.

\subsection{Crystal structure and microstructure analysis}

Rietveld analysis. The experimental XRD patterns of all three samples, Z18, F28 and MZ17, were fitted using FullProf program based on the Rietveld method. Different combinations of the isotropic/anisotropic size and strain broadening were considered during refinement of the microstructural parameters. A rather good agreement between the experimental and modeled XRD pattern was obtained when an anisotropic size broadening wás considered, regardless whether the isotropic or anisotropic strain broadening was applied. For these two models, the obtained values for all refined parameters overlapped within the standard deviations (table S1). Further improvement in the refinement (lower goodness-of-fit, $G o F$ ) was achieved when, in addition to the anisotropic size broadening (which contribute to the Lorentzian component of the profile function), we introduced a contribution of an isotropic size broadening via a Gaussian function, and kept the isotropic strain broadening model [36]. Following this model, we observed decrease of the average apparent size (App-Size) values for about $11 \%$ (in $\mathbf{Z 1 8}$ and MZ17) and $16 \%$ (in F28), and the average maximum strain values for more than 50\% (MaxStrain $=1 / 4$ apparent strain Stokes-Wilson), compared to the values obtained following previous models. The comparative analysis of the refined structural and microstructural parameters for each applied model, as well as the refined and calculated cation-oxygen bond distances and the reliability factors are given for the sample $\mathbf{Z 1 8}$ in the Supplementary (table S1).

Although the best agreement between the experimental and refined XRD data (the lowest $G o F$ ) gave the model: (isotropic+anisotropic) size and isotropic strain broadening, the results presented here are obtained in the frame of the model which considers an anisotropic size broadening and an anisotropic strain broadening. One of the reasons for this is that we were able to refine all parameters simultaneously, what is not quite common situation for nanocrystals (therefore, is interesting to show). The second reason is that the shape of Z18 nanocrystallites obtained upon refinement the XRD data in this model fits in the best way the real shape of nanoparticles observed by HRTEM (figure 2(b) and 2(d)). The experimental and refined XRD data of the samples Z18, F28 and MZ17 applying a model which consider an anisotropic size 
broadening and an anisotropic strain broadening contribution, as well as the projection on $x y$ plane of the average crystallite size and the average maximum strain in the reciprocal space, are shown in figure 3, while the main results of the Rietveld refinement are summarized in table 2.
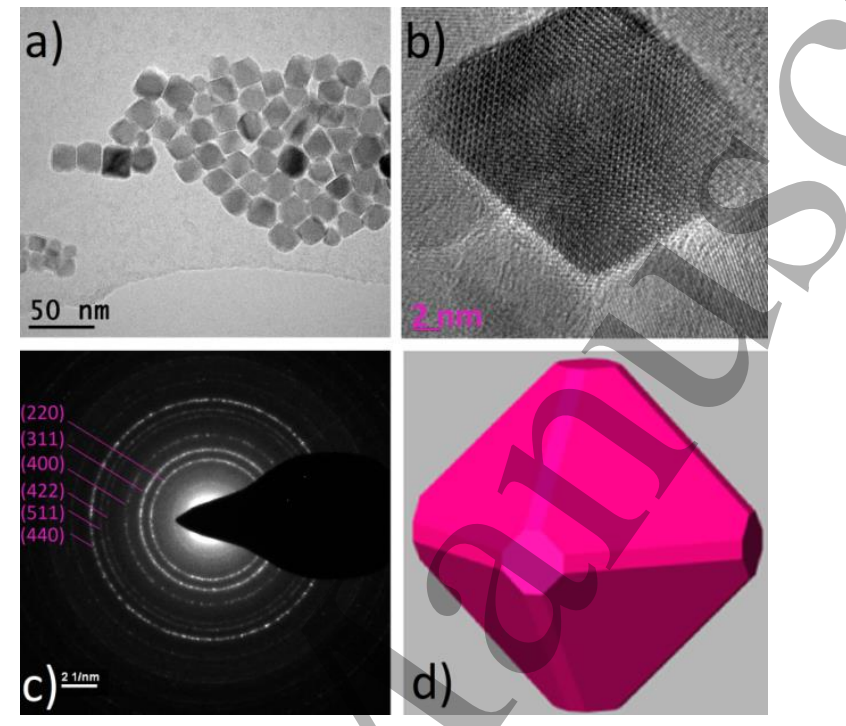

Figure 2. (a_b) HRTEM images and (c) SAED (selected area electron diffraction) pattern of the sample Z18; (d) shape of $\mathbf{Z 1 8}$ nanoparticle obtained applying anisotropic size and anisotropic strain broadening model. 

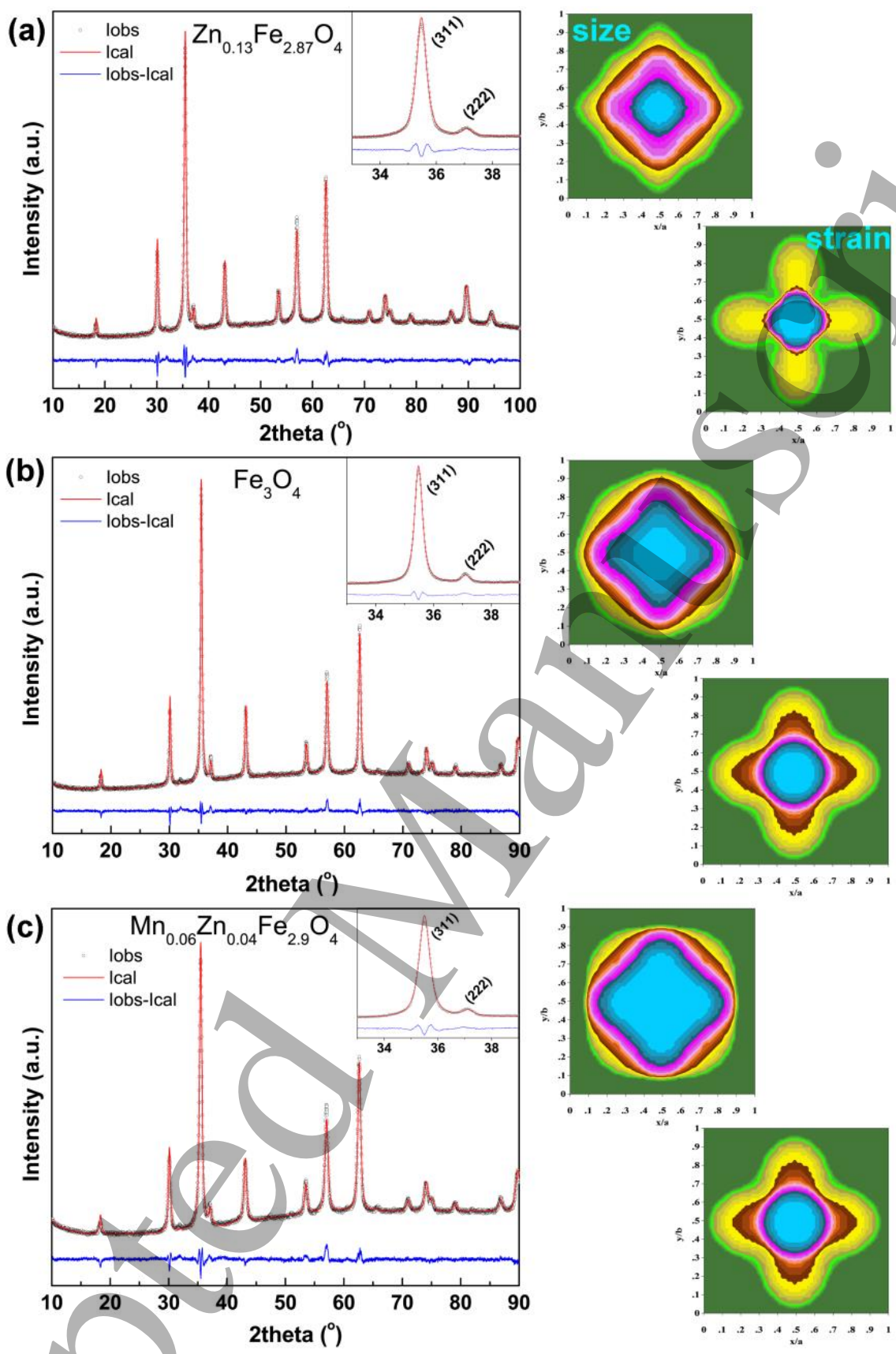

Figure 3. (left): Refined XRD patterns of the samples Z18 (a), F28 (b), and MZ17 (c) in a model which consider an anisotropic size broadening and an anisotropic strain broadening contribution. (right): Visualization of the average crystallite size and the average maximum strain in the reciprocal space (projection on $x y$-plane), obtained from refinement of the patterns by GFOURIER program. 
Lattice parameters show typical values of bulk magnetite and vary slightly by changing the composition, $a=(8.391-8.396) \AA$. Slight increase of the lattice parameter, $a$, in $\mathrm{Zn}$-doped sample, Z18, compared to the unsubstituted magnetite, $\mathbf{F 2 8}$, indicates that the $\mathrm{Zn}^{2+}$ ions are incorporated into the tetrahedrally coordinated, A-sites in the spinel lattice. Oppositely, slight decrease of the lattice parameter in (Mn,Zn)-containing sample, MZ17, compared to F28, could be an indication that some $\mathrm{Mn}^{2+}$ ions are oxidized into $\mathrm{Mn}^{3+}$ and sited at/octahedrally coordinated, B-sites, replacing $\mathrm{Fe}^{2+}$ ions.

Microstructural analysis showed that the size of coherent domains, $d_{\mathrm{XRD}}$, for applied

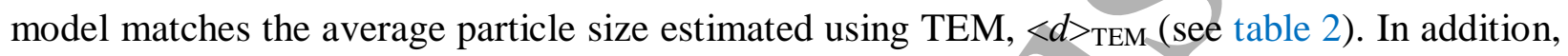
the shape of Z18 nanocrystallites obtained upon refinement the XRD data fits the shape observed by HRTEM (figures 2(b) and 2(d)). A low value of the applied maximum strain (i.e. the microstrain) is obtained in all three samples indicating the low dénsity of crystal imperfections. The low density of crystal imperfections is also confirmed in the sample Z18 by HRTEM observation (figure 2(b)). In substituted $\mathrm{Fe}_{3} \mathrm{O}_{4}$ cuboctahedral nanoparticles, $\mathbf{Z 1 8}$ and MZ17, with similar particle size and substitution level, $x(x=0.13$ and $x=0.10$, respectively), microstrain is almost of the same order, while in the unsubstituted magnetite $\mathbf{F 2 8}$, microstrain decreases (table 2). Presumably, the density of crystal imperfections in nanocrystals synthesized by thermal decomposition method can be inversely related with a particle size and/or substitution level.

Table 2. The results of Rietveld refinement of XRPD patterns of samples 1-Z18, 2-F28 and 3MZ17 in the model which consider a combination of an anisotropic size broadening and an anisotropic strain broadening.

\begin{tabular}{|l|l|l|l|}
\hline Sample & $\mathbf{1 - Z 1 8}$ & $\mathbf{2 - F 2 8}$ & $\mathbf{3 - M Z 1 7}$ \\
\hline Composition & $\mathbf{Z n}_{\mathbf{0 . 1 3}} \mathrm{Fe}_{\mathbf{2 . 8 7}} \mathbf{O}_{4}$ & $\mathbf{F e}_{\mathbf{3}} \mathbf{O}_{\mathbf{4}}$ & $\mathbf{M n}_{\mathbf{0 . 0 6}} \mathbf{Z n}_{\mathbf{0 . 0 4}} \mathrm{Fe}_{\mathbf{2 . 9}} \mathbf{O}_{\mathbf{4}}$ \\
\hline Occupancy set up at: & $\begin{array}{l}\left(\mathrm{Zn}^{2+}{ }_{0.13} \mathrm{Fe}^{3+}{ }_{0.87}\right) \\
{\left[\mathrm{Fe}^{2+}{ }_{0.87} \mathrm{Fe}^{3+}{ }_{1.13}\right] \mathrm{O}_{4}}\end{array}$ & $\begin{array}{l}\left(\mathrm{Fe}^{3+}\right) \\
{\left[\mathrm{Fe}^{2+} \mathrm{Fe}^{3+}\right] \mathrm{O}_{4}}\end{array}$ & $\begin{array}{l}\left(\mathrm{Mn}^{2+}{ }_{0.03} \mathrm{Zn}^{2+}{ }_{0.04} \mathrm{Fe}^{3+}{ }_{0.93}\right) \\
{\left[\mathrm{Fe}^{2+} \mathrm{Fe}^{3+}{ }_{0.97} \mathrm{Mn}^{3+}{ }_{0.03}\right] \mathrm{O}_{4}}\end{array}$ \\
\hline $\begin{array}{l}\left.\text { Average particle size, }\langle d\rangle_{\mathrm{TEM}}\right\rangle \\
(\mathrm{nm})\end{array}$ & $18.3 \pm 4.0$ & $28 \pm 10$ & $17.2 \pm 4.8$ \\
\hline Average App-Size, $d_{\text {XRD }}(\mathrm{nm})$ & $19.7(2.0)^{\#}$ & $25.9(1.6)^{\#}$ & $16.1(1.1)^{\#}$ \\
\hline along [111] & 17.7 & 23.6 & 14.2 \\
along [110] & 20.7 & 28.0 & 17.5 \\
along [100] & 24.7 & 27.6 & 17.0 \\
\hline Applied Max-Strain $\left(\times 10^{-4}\right)$ & $21(8)$ & $13(2)$ & $21(8)$ \\
\hline Density, $\rho\left(\mathrm{g} / \mathrm{cm}^{3}\right)$ & 5.224 & 5.202 & 5.212 \\
\hline
\end{tabular}




\begin{tabular}{|l|l|l|l|}
\hline Lattice constant, $a(\AA)$ & $8.3965(1)$ & $8.3934(2)$ & $8.3917(1)$ \\
\hline Oxygen parameter, $\boldsymbol{u}$ & $0.2528(2)$ & $0.2518(2)$ & $0.2532(2)$ \\
\hline
\end{tabular}

\# measure of anisotropy, no standard deviation

\subsection{Mössbauer spectra analysis}

To observe changes in the local environment of $\mathrm{Fe}$ ions caused by substituting $\mathrm{Fe}^{3+}$ ions with $\mathrm{Zn}^{2+}$ or $\left(\mathrm{Zn}^{2+} / \mathrm{Mn}^{2+/ 3+}\right)$ in the spinel lattice, we used the Mössbauer spectroscopy. The experimental and fitted zero-field transmission Mössbauer spectra of Z18, F28 and MZ17 samples, collected at ambient conditions, are shown in figure 4. All three spectra are composed of two magnetic components typical for magnetite, representing two inequivalent A (tetrahedral) and $\mathrm{B}$ (octahedral) $\mathrm{Fe}$ ion positions in the spinel $\mathrm{AB}_{2} \mathrm{O}_{4}$ structure [37]. No characteristic paramagnetic components appear despite the nanoparticulate nature of the samples indicating that all particles are blocked at room temperature $\left(\mathrm{T}_{\mathrm{B}}^{\text {Möss }}>\mathrm{RT}\right.$ ) for the experimental time window of measurements defined by the Mössbauer spectroscopy $\left(\tau_{\text {meas }}{ }^{\text {Möss }}=\tau_{\text {Larmor }} \approx 10^{-8}-10^{-9} \mathrm{~s}\right.$ for ${ }^{57} \mathrm{Fe}$ ). The RT spectra of samples F28, Z18 and MZ17 were fitted with two, three and four magnetic sextets, respectively, giving the best results. The fitted hyperfine parameters values are summarized in table 3.

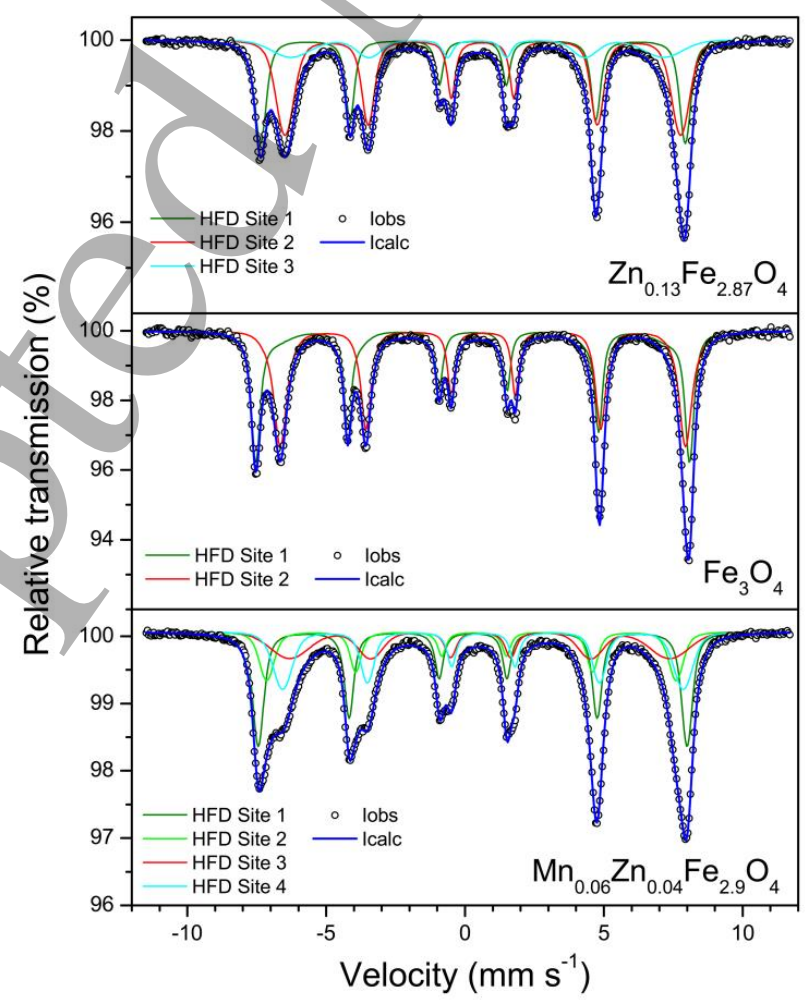


Figure 4. The room temperature Mössbauer spectra of sample Z18, F28 and MZ17. In substituted samples, Z18 and MZ17, the background was adjusted with an addition of a broad singlet line (with zero quadrupole splitting).

Table 3. Fitted room temperature Mössbauer parameters: $\delta$ - isomer shift, $B_{\text {hf }}-$ magnetic hyperfine field, $\varepsilon$ - quadrupole shift and $\Gamma_{\exp }$ line width, for Z18, F28 and MZ17 samples.

\begin{tabular}{|c|l|c|c|c|c|}
\hline Sample & assignment & $\begin{array}{c}\boldsymbol{\delta} \\
\left(\mathbf{m m ~ s}^{-\mathbf{1}}\right)\end{array}$ & $\begin{array}{c}\boldsymbol{B}_{\mathbf{h f}} \\
(\mathbf{T})\end{array}$ & $\begin{array}{c}\boldsymbol{\varepsilon} \\
(\mathbf{m m ~ s})\end{array}$ & $\begin{array}{c}\text { Ratio } \\
(\%)\end{array}$ \\
\hline F28 & $\mathrm{A}_{1}:\left(\mathrm{Fe}^{3+}\right)^{\mathrm{tet}}$ & 0.29 & 47.7 & -0.008 & 45.6 \\
& $\mathrm{~B}_{1}:\left(\mathrm{Fe}^{2+} / \mathrm{Fe}^{3+}\right)^{\text {oct }}$ & 0.65 & 45.3 & -0.008 & 48.9 \\
\hline Z18 & $\mathrm{A}_{1}:\left(\mathrm{Fe}^{3+}\right)^{\text {tet }}$ & 0.29 & 47.2 & -0.006 & 36.3 \\
& $\mathrm{~B}_{1}:\left(\mathrm{Fe}^{2+} / \mathrm{Fe}^{3+}\right)^{\text {oct }}$ & 0.65 & 44.1 & -0.007 & 44.3 \\
& $\mathrm{~B}_{2}:\left(\mathrm{Fe}^{2+} / \mathrm{Fe}^{3+}\right)^{\text {oct }}$ & 0.49 & 41.3 & 0.054 & 15.5 \\
& & & & & \\
\hline MZ17 & $\mathrm{A}_{1}:\left(\mathrm{Fe}^{3+}\right)^{\mathrm{tet}}$ & 0.28 & 47.9 & -0.007 & 31.4 \\
& $\mathrm{~A}_{2}:\left(\mathrm{Fe}^{3+}\right)^{\mathrm{tet}}$ & 0.28 & 45.7 & -0.050 & 16.51 \\
& $\mathrm{~B}_{1}:\left(\mathrm{Fe}^{2+} / \mathrm{Fe}^{3+}\right)^{\text {oct }}$ & 0.65 & 44.7 & -0.009 & 24.27 \\
& $\mathrm{~B}_{2}:\left(\mathrm{Fe}^{2+} / \mathrm{Fe}^{3+}\right)^{\text {oct }}$ & 0.55 & 42.5 & -0.020 & 20.80 \\
\hline
\end{tabular}

Mössbauer spectrum of unsubstituted $\mathrm{Fe}_{3} \mathrm{O}_{4}$ (F28). Mössbauer spectrum of the sample F28, which is by EDX measurements identified as unsubstituted magnetite, was fitted with two magnetic components belonging to $\mathrm{Fe}$ ions on sites with different local surrounding. The magnetic sextet $A_{1}$ with lower isomer shift, $\breve{u}$ and a higher hyperfine field, $B_{h f}$ was attributed to the $\mathrm{Fe}^{3+}$ ions residing on the $\mathrm{A}$ sites. The second component, $\mathrm{B}_{1}$ was assigned to the mixture of $\mathrm{Fe}^{3+}$ and $\mathrm{Fe}^{2+}$ ions at the $\mathrm{B}$ sites. The quadrupole shift, $\varepsilon$ was find to be close to zero for both sites indicating symmetric charge distribution around iron nucleus. The values of the fit parameters are in good agreement with values reported in the literature for pure magnetite (even though the hyperfine fields are somewhat lower than the ones obtained for bulk magnetite) [38, 39]. However, the obtained ratio of spectral areas of $\mathrm{A}$ and $\mathrm{B}$ sextets, of $R_{\mathrm{A} / \mathrm{B}}=0.97$, for $\mathbf{F} 28$ sample is significantly higher than the theoretical value 0.5 predicted for stoichiometric magnetite (this value is valid if the same recoil fraction is assumed for both A and B sites, and it can be slightly larger if the recoil fraction is assumed to be larger for A sites [37]). The literature results revealed that for $\mathrm{Fe}_{3} \mathrm{O}_{4}, R_{\mathrm{A} / \mathrm{B}}=1.09 \pm 0.04$ at room temperature [40]. Accordingly, we could expect a possible nonstoichiometry of the sample (the intensity of B line relative to the A line 
reduces in nonstoichiometric magnetite [41]). This points out to the presence of larger amount of $\mathrm{Fe}^{3+}$ ions in the sample, indicating that the sample contains a certain amount of maghemitized magnetite [23, 42]. The broadening of the inner sextet compared to the outer one additionally indicates that our sample can be consisted of partially oxidized magnetite. Since the oxidation of magnetite is followed by the vacancy formation, the nonstoichiometric magnetite can be represented in the following form: $\left(\mathrm{Fe}^{3+}\right)_{\mathrm{A}}\left[\left(\mathrm{Fe}^{2+} \mathrm{Fe}^{3+}\right)_{2-6 \mathrm{x}}\left(\mathrm{Fe}^{3+}\right)_{5-\mathrm{x}}(\square)_{\mathrm{x}}\right]_{\mathrm{B}} \mathrm{O}_{4}$, where $\triangle$ stand for a vacancy (it is assumed that vacancy are formed exclusively on the octahedral sites of the spinel structure) [43]. Following procedure from the paper of Costa et al [43] we were able to estimate the amount of vacancies in the sample. It was found that the chemical formula of the sample F28 can be $\mathrm{Fe}_{2.92} \mathrm{O}_{4}$. The estimated number of vacancies are in concordance with the previous Mössbauer studies on nonstoichiometric partially oxidized magnetite [43, 44]. However it should be noted that the lattice parameter evaluated from the XRD analysis and the observed Verwey transition temperature at $\sim 117 \mathrm{~K}$ (see figure 5 (a)) correspond to the magnetite with less number of vacancies [45]. Therefore we conclude that our sample F28 probably comprises particles whose outer shell layer consists of oxidized $\mathrm{Fe}^{2+}$ ions while the nucleus consists of pure magnetite [46, 47].

Mössbauer spectrum of $\mathrm{Zn}$-substituted $\mathrm{Fe}_{3} \mathrm{O}_{4}$ (Z18). It can be readily seen that, compared to unsubstituted $\mathrm{Fe}_{3} \mathrm{O}_{4}, \mathbf{F 2 8}$, the spectrum of $\mathrm{Zn}$-doped $\mathrm{Fe}_{3} \mathrm{O}_{4}, \mathbf{Z 1 8}$, displays less resolved sextets which is the result of incorporation of the nonmagnetic $\mathrm{Zn}^{2+}$ ions at $\mathrm{A}$ sites of the magnetite spinel structure. It was reported that for low values of $\mathrm{Zn}$ doping $(\mathrm{x}<0.4[18]$ or $\mathrm{x}<1 / 3$ [48]), the $\mathrm{Zn}$ ions preferentially occupy A sites which leads to broadening of the $\mathrm{B}$ absorption lines. Namely; incorporation of nonmagnetic $\mathrm{Zn}^{2+}$ ion at the A sites cause the break of four magnetic A-B connections [22], thus leading to the weakening of A-O-B superexchange interactions and, consequently to the lowering of hyperfine fields values. Random distribution of $\mathrm{Zn}$ ions on A sites produces non-uniform hyperfine fields on B-sites, thus causing the line broadening of inner sextets. Therefore, the Mössbauer spectrum of Zn-substituted magnetite (figure 4), with composition $\mathrm{Zn}_{0.13} \mathrm{Fe}_{2.87} \mathrm{O}_{4}$ predicted by $\mathrm{EDX}$ analysis, was fitted with three sextets. The sextet $\mathrm{A}_{1}$ was assigned to the $\mathrm{Fe}^{3+}$ ions at $\mathrm{A}$ sites, while the two sextets, $\mathrm{B}_{1}$ and $\mathrm{B}_{2}$, with higher values of the isomer shift, $\breve{u}$ and lower hyperfine field values, $B_{\mathrm{hf}}$ were attributed to the $\mathrm{Fe}^{2+/ 3+}$ ions residing on $\mathrm{B}$ sites (see table 3). Due to the decreased magnetic coupling strength between $\mathrm{Fe}^{3+}$ in $\mathrm{A}$ and $\mathrm{B}$ sites (invoked by non-magnetic substitution on A-sites), hyperfine 
fields values are slightly lower for the sample $\mathbf{Z 1 8}$ compared to the sample F28. A smaller $\mathrm{B}_{\mathrm{hf}}$ value of component $\mathrm{B}_{2}$ can be associated with a part of iron ions on $\mathrm{B}$ sites which are coupled with lower number of $\mathrm{Fe}^{3+}$ ions on A-sites. In addition, the lower isomer shift value of the components assigned to the octahedral B-sites, $\breve{\mathrm{B}}_{\mathrm{B}}$ (isomer shift of A sites remains almost unchanged) is due to the increased number of $\mathrm{Fe}^{3+}$ ions on the $\mathrm{B}$ sites. This excess of $\mathrm{Fe}^{3+}$ ions appears as a consequence of the fact that the neutral charge balance requires one $\mathrm{Fe}^{2+}$ ion on $\mathrm{B}$ site to be oxidized to $\mathrm{Fe}^{3+}$, for each $\mathrm{Fe}^{3+}$ on $\mathrm{A}$ site replaced by $\mathrm{Zn}^{2+}$ ion, or some vacancies to be generated at B sites [48]. The relative spectral area between A and B components is significantly reduced $\left(R_{\mathrm{A} / \mathrm{B}}=0.61\right)$ in $\mathbf{Z 1 8}$, due to $\mathrm{Fe}^{3+}$ ions replacement. Here is worth to remember that for low density of vacancies and low degree of iron substitution, the rapid/electron hopping process between $\mathrm{Fe}^{2+}$ and $\mathrm{Fe}^{3+}$ ions on B-sites will not be suppressed at room temperatrure [49].

Mössbauer spectrum of (Mn,Zn)-substituted $\mathrm{Fe}_{3} \mathrm{O}_{4}$ (MF17). The Mössbauer spectrum of the $\mathrm{Zn}$ and $\mathrm{Mn}$ ions substituted $\mathrm{Fe}_{3} \mathrm{O}_{4}$ sample, MF17, having stoichiometry $\mathrm{Mn}_{0.06} \mathrm{Zn}_{0.04} \mathrm{Fe}_{2.9} \mathrm{O}_{4}$, is drastically altered compared to the other two samples. For thus low doping, $\mathrm{Zn}^{2+}$ ions enter only A sites replacing $\mathrm{Fe}^{3+}$ ions, while the XRD analysis indicates that Mn ions probably replace Fe ions on both A- and B-sites. Nevertheless, even a small amount of Mn-substituted sample strongly affects the shape and the intensity of the spectrum [50, 51]. Replacement of iron by manganese ions is evidenced by the high broadening and decreased intensity of both, and especially inner band associated with octahedral (B) sites. A more pronounced decrease of the $\mathrm{B}$ component intensity can be an indication that manganese ions occupies B-sites [50]. The best fit of the Mössbauer spectrum was obtained when it was fitted with four components (two for tetrahedral and two for octahedral Fe sites). Two sextets, $A_{1}$ and $\mathrm{A}_{2}$, having the same value of isomer shifts $(\breve{u}=0.28 \mathrm{~mm} / \mathrm{s})$, but different values of hyperfine fields, are assigned to the $\mathrm{Fe}^{3+}$ ions on the A-sites with nonequivalent environments. Accordingly, part of the $\mathrm{Fe}^{3+}$ ions $\left(\mathrm{A}_{2}\right)$ are subjected to hyperfine field with lower $\mathrm{B}_{\mathrm{hf}}$ values, but larger qudrupole shift, $\varepsilon$, implying slight distortion of charge symmetry around $\mathrm{Fe}^{3+}$ ions on the tetrahedral sites. It is probably due to the presence of manganese ions on B sites which introduce the Jahn-Teller distortion of crystal field symmetry [41, 51, 52]. Based on this result, in the final refinement of the XRD data of sample MZ17, the cation occupancy was set up so that some Mn ions occypy the $\mathrm{B}$ sites. Another set of two magnetic components, $\mathrm{B}_{1}$ and $\mathrm{B}_{2}$, with larger isomer shifts, $\breve{\mathrm{u}}$ and smaller hyperfine fields, $\mathrm{B}_{\mathrm{hf}}$ (table 3), were assigned to the $\mathrm{Fe}^{2+}$ and $\mathrm{Fe}^{3+}$ ions on the 
B-sites. The component $\mathrm{B}_{2}$ originates from parts of the lattice where iron ions have larger number of non-magnetic ions as neighbors on A sites (therefore reduced hyperfine field), and where larger number of iron ions are oxidized to $\mathrm{Fe}^{3+}$ (therefore smaller isomer shift) [37, 53]. The other component, $\mathrm{B}_{1}$, having hyperfine parameters similar to those of pure magnetite sample, can be again ascribed to the $\mathrm{Fe}^{2+} / \mathrm{Fe}^{3+}$ ions on octahedral sites with electron hopping occurring in a "regular" environment, i.e. not having zinc and manganese ions ás neighbors. Somewhat reduced hyperfine field values of the components assigned to the B sites is in concordance with previous findings on Mn doping decreasing the hyperfine fields for these sites [54].

In conclusion, the isomer shift values for $\mathrm{A}_{1}, \mathrm{~A}_{2}$ and $\mathrm{B}_{1}$ components $\left(\delta_{\text {tet }}\right.$ and $\left.\delta_{\text {oct }}\left(\mathrm{B}_{1}\right)\right)$ were found to be almost the same in all three samples, indicating that the ${ }^{57} \mathrm{Fe}$ ions on the tetrahedral $(A)$ and partially on the octahedral $\left(B_{1}\right)$ sites of spinel lattice see no changes in the electron density with the variation in particle size and the composition. Upon substitution with $\mathrm{Zn}$ or $(\mathrm{Mn}, \mathrm{Zn})$ ions, broadening of the magnetic sextets was observed, inferring the introduction of additional component(s) (one for $\mathrm{Zn}$ - and two for (Mn,Zn)-substituted sample). The additional component, delineated to the ${ }^{57} \mathrm{Fe}$ ions on octahedral $\mathrm{B}_{2}$ sites, has the lower $\delta_{\text {oct }}$ value and weaken hyperfine magnetic fields, and can be explained as being due to the distortion in the Bsites invoked by non-magnetic substitution in the A-sublattice. At the same time, the partial oxidation of $\mathrm{Fe}^{2+}$ ions at $\mathrm{B}$-sites takes place. The second component $\mathrm{A}_{2}$ introduced to delineate the Mössbauer spectrum of sample MZ17 was assigned to the ${ }^{57} \mathrm{Fe}$ ions on tetrahedral A-sites which feel distortion invoked by substitution on the B-sites, probably with manganese ions. Manganese ions has high ability to change valence state, and as $\mathrm{Mn}^{3+}$ it has high preference for B-sites, where can introduce additional increases of the linewidth of B components by invoking Jahn-Teller distortion $[41,52])$. It is worth noting that no additional components which could be associated to $\alpha-\mathrm{Fe}_{2} \mathrm{O}_{3}, \gamma-\mathrm{Fe}_{2} \mathrm{O}_{3}$ or $\mathrm{FeO}$ phase, were observed in the Mössbauer spectra in all three samples: nano- $\alpha-\mathrm{Fe}_{2} \mathrm{O}_{3}$ has higher $B_{\mathrm{hf}} \approx 51.5 \mathrm{~T}$ at $\mathrm{RT}[55] ; \gamma-\mathrm{Fe}_{2} \mathrm{O}_{3}$ has very symmetric Mössbauer spectra at RT [50, 56, 57]; while FeO phase should give the nonmagnetic contribution to the Mössbauer spectra since its Néel temperature is $\mathrm{T}_{\mathrm{N}} \approx 200 \mathrm{~K}$ [31].

\subsection{Magnetic characterization.}


Magnetic responses of unsubstituted, $\mathrm{Zn}$ - and ( $\mathrm{Mn}, \mathrm{Zn}$ )-substituted $\mathrm{Fe}_{3} \mathrm{O}_{4}$ powdered nanoparticles in a static (DC) magnetic field were studied from measurements of the field and temperature dependence of DC magnetization, $M(\mathrm{H})$ and $M(\mathrm{~T})$. To calculate mass magnetization of samples, we performed TGA/DTA analysis. The weight loss due to evaporation of organic phase, gave the residue corresponding to $94.7,96.5$ and 92.2 wt.\% of the original weight of samples Z18, F28 and MZ17, respectively (see figure S5). Thus obtained weight loss was re-calculated taking into account that during TGA/DTA experiment the partial oxidation takes place bringing in a mixture of hematite and magnetite phases (proved by the XRD analysis).

The zero-field-cooled magnetization curves $\left(M_{\mathrm{ZFC}}\right.$, figure 5(a)) do not rich the maximum in a field of $7.96 \mathrm{kA} / \mathrm{m}(100 \mathrm{Oe})$ up to $300 \mathrm{~K}$, suggesting the existence of strong interparticle interactions. The magnetic dipole-dipole interactions modify the energy barrier $q E_{\mathrm{A}}\left(=K_{\mathrm{eff}} \mathrm{V} ; K_{\mathrm{eff}}\right.$ is an effective anisotropy constant), and shift the average blocking temperature, $\left\langle\mathrm{T}_{\mathrm{B}}\right\rangle$, to higher temperature range [14]. The drop of $M_{\mathrm{ZFC}}$ value observed in the sample $\mathbf{F 2 8}$ at $\mathrm{T}_{\mathrm{V} \approx 117 \mathrm{~K} \text { is }}$ assigned to the Verwey transition, which should involves slight distortion of the crystal structure and change in the symmetry of crystal lattice from face centered cubic (f.c.c) to rhombohedral [58]. Consequently, it should bring about the transformation of the magnetocrystalline anisotropy symmetry from cubic to uniaxial when passing from $\mathrm{T}>\mathrm{T}_{\mathrm{V}}$ to $\mathrm{T}<\mathrm{T}_{\mathrm{V}}$ [42]. Since, in high-purity magnetite, the Verwey temperature $\mathrm{T}_{\mathrm{V}}$ range between 110 and $125 \mathrm{~K}$ [59], we can assume that the core of $\mathbf{F 2 8}$ nanoparticles has stoichiometry very close to pure $\mathrm{Fe}_{3} \mathrm{O}_{4}$ [41]. On the contrary, in doped Z18 and MZ17 nanoparticles, the Verwey transition has not been experimentally observed owing to the stoichiometry deviations in samples caused by the presence of chemical dopants $[60,61]$. A sudden slope change in the ZFC magnetization curve, which occurs at $\mathrm{T}_{\mathrm{S}} \sim 40$ $\mathrm{K}$ in all three samples (figure 5(a)), could come from the relaxation processes occurring in particles with smaller size or the freezing associated with the frustrated interactions among surface spins $[23,62]$.

The hysteresis loops of all three samples, recorded at 300 and $5 \mathrm{~K}$, are shown in figure 5 b_c. The $M_{\mathrm{S}}, H_{\mathrm{C}}$ and $M_{\mathrm{R}}$ values are extracted and given in the table 4 . At $5 \mathrm{~K}$, the samples show a ferromagnetic behavior, with the $H_{\mathrm{C}}$ value similar in the substituted samples $\mathbf{Z 1 8}$ and MZ17, and somewhat higher coercivity, $H_{\mathrm{C}}$, in the pure $\mathbf{F 2 8}$ magnetite. At $300 \mathrm{~K}$, only unsubstituted 28 nm-sized $\mathrm{Fe}_{3} \mathrm{O}_{4}$ nanoparticles show the remanence and coecivity, while in the samples, $\mathbf{Z 1 8}$ and MZ17, $H_{\mathrm{C}}$ and $M_{\mathrm{R}}$ are zero at $300 \mathrm{~K}$. It means that the ensemble of $28 \mathrm{~nm}$-sized unsubstituted 
$\mathrm{Fe}_{3} \mathrm{O}_{4}$ nanoparticles exhibit weak ferrimagnetic features at $300 \mathrm{~K}$ coming from the part of nanoparticles which size exceeds the critical value for superparamagnetic behavior and, therefore, the thermal energy is not enough to overcome the energy barrier, $q \propto E_{\mathrm{A}}$. The saturation magnetization values, $M_{\mathrm{S}}$ at $5 \mathrm{~K}$ range from $91.2 \mathrm{Am}^{2} / \mathrm{kg}$ (sample $\mathrm{MZ17}$ ) to $98.6 \mathrm{Am}^{2} / \mathrm{kg}_{\mathrm{Fe} 3 \mathrm{O} 4}$ (sample Z18), overcoming the $M_{\mathrm{S}}$ value of bulk magnetite $\left(\sim 95 \mathrm{Am}^{2} / \mathrm{kg}\right)$ in Zn-substituted sample (table 4). With increasing temperature up to $300 \mathrm{~K}, M_{\mathrm{S}}$ value remains high in $\mathbf{Z 1 8}$ and F28 (see table 4), indicating the good crystalinity and low density of the structural defects in magnetite particles with size below $30 \mathrm{~nm}$ [63]. The maghemitized surface layer, predicted by Mössbauer spectra analysis in F28, as well as the surface spin disorder, have a minor (decreasing) effect on the $M_{\mathrm{S}}$ value.
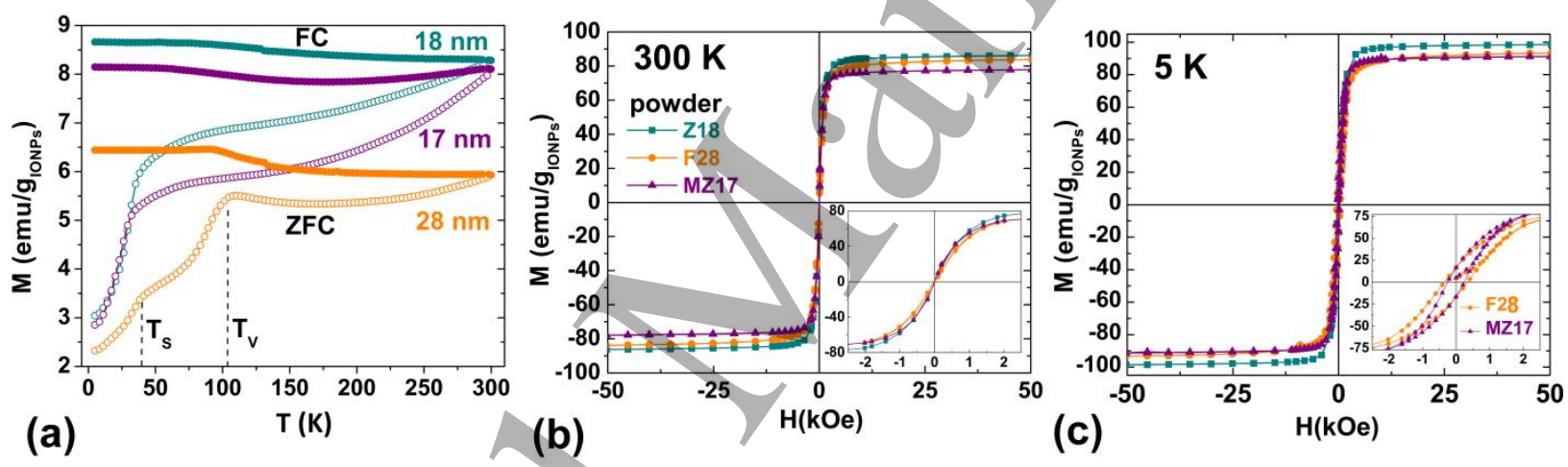

Figure 5. (a) ZFC and FC magnetizations as a function of temperature, measured with an external applied field of $7.96 \mathrm{kA} / \mathrm{m}$ (100 Oe); (b_c) the hysteresis loops of unsubstituted (F28), and Zn- (Z18) and (Mn,Zn)-substituted (MZ17) magnetite nanoparticles recorded at $300 \mathrm{~K}$ (b) and $5 \mathrm{~K}(\mathrm{c})$.

Table 4. Saturation magnetization $\left(\boldsymbol{M}_{\mathbf{S}}\right)$, coercitive field $\left(\boldsymbol{H}_{\mathbf{C}}\right)$, ratio $\boldsymbol{M}_{\mathbf{R}} / \boldsymbol{M}_{\mathbf{S}}$ and the magnetic moment per formula unit ( $\boldsymbol{\mu}_{\text {eff }}$, estimated from the hysteresis loops measured at 300 and $5 \mathrm{~K}$; an effective anisotropy constant $\left(\boldsymbol{K}_{\text {eff }}\right)$ at $5 \mathrm{~K}$ estimated from slow, DC magnetic measurements; the heating efficiency of ferrofluids expressed by the specific absorption rate $(\boldsymbol{S} \boldsymbol{A R})$, measured in the AC magnetic field $\left(H_{0}=23.87 \mathrm{kA} / \mathrm{m}\right.$ and $f=228 \mathrm{kHz}$ (for $\mathbf{Z 1 8}$ and $\mathbf{F 2 8}$ ) or $252 \mathrm{kHz}$ (for MZ17)); the intrinsic loss parameter (ILP). 


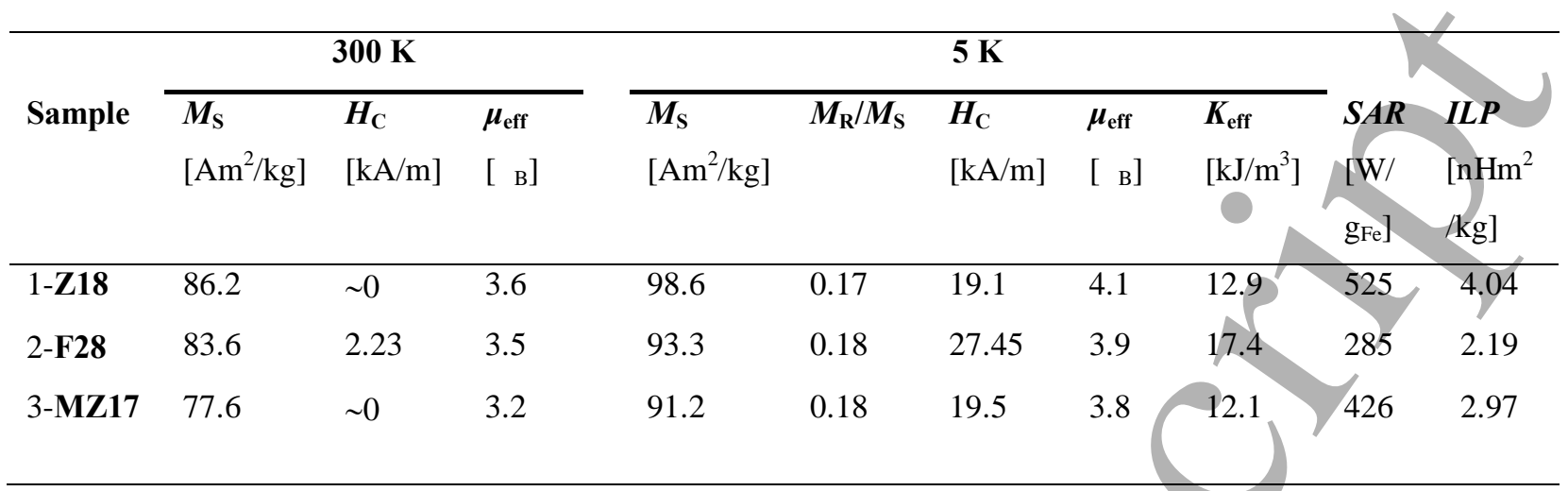

In order to estimate the effective magnetic anisotropy constant $K_{\text {eff }}$, we have used a simple analytical approach based on the relation between the coercivity of magnetic nanoparticles, $H_{\mathrm{C}}$, and the magnetic anisotropy energy of single domain nanoparticles, $q E_{\mathrm{A}}$, with uniaxial symmetry, represented by the equation: $\mu_{0} H_{\mathrm{C}}=0.48\left(2 K_{\mathrm{eff}} / M_{\mathrm{S}}\right)\left[1-\left(\mathrm{T} / \mathrm{T}_{\mathrm{B}}\right)^{\gamma}\right][33,64]$. The fact that $K_{\text {eff }}$ of the ensemble of magnetic nanoparticles depends on the distribution of the easy axes of magnetization in space is partially delineated with the parameter $\gamma$, which takes value 0.77 for an ensemble of randomly oriented particles and 0.5 for an ensemble of aligned particles [65]. In our case the term $\left(\mathrm{T} / \mathrm{T}_{\mathrm{B}}\right)$ can be neglected, since the ZFC-FC magnetization measurements point out that the blocking temperature of samples is high. Thus, using the simplified formula, $K_{\mathrm{eff}}=\varepsilon_{0} H_{\mathrm{C}} M_{\mathrm{S}} / 0.96$, the experimental $H_{\mathrm{C}}$ and $M_{\mathrm{S}}$ values obtained from the hysteresis loops at $5 \mathrm{~K}$ (table 4), as well as the density of material, $\rho$ given as the output of XRD refinements, we estimated $K_{\text {eff }}$ values of $12.9,17.4$ and $12.1 \mathrm{~kJ} / \mathrm{m}^{3}$ for $\mathbf{Z 1 8}, \mathbf{F 2 8}$ and $\mathbf{M Z 1 7}$, respectively. These values are rather consistent with those found in the literature [66]. Just to note that the $K_{\text {eff }}$ value will be increased for approximately $6 \%$ in $\mathbf{Z 1 8}$ and MZ17, e.g. $4 \%$ in F28, considering the random distribution of nanoparticles, and maximum $\sim 15 \%$ for an assembly of aligned nanocrystallites $(\gamma=0.5)$ (we suppose the $\mathrm{T}_{\mathrm{B}}$ lies between 200 and $300 \mathrm{~K}$ in the substituted, and $-300 \mathrm{~K}$ in unsubstituted $\mathrm{Fe}_{3} \mathrm{O}_{4}$ ). Even with such increments, $K_{\text {eff }}$ would be below $20 \mathrm{~kJ} / \mathrm{m}^{3}$.

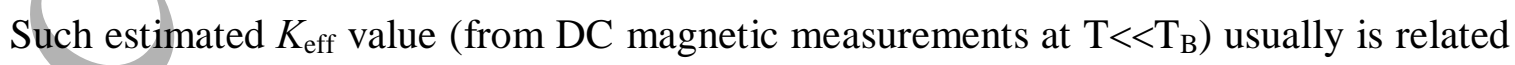
to the single-particle anisotropy properties at room temperature $[67,68]$. According to it, the $K_{\text {eff }}$ value in the substituted samples, Z18 and MZ17, is very close to the first order magnetocrystalline anisotropy constant, $K_{1}$ of bulk magnetite regarding the cubic symmetry 
(intermediate literature value for $K_{1}\left(\mathrm{Fe}_{3} \mathrm{O}_{4}\right)$ is between 11 and $14 \mathrm{~kJ} / \mathrm{m}^{3}$ [23, 42, 69]. In unsubstituted $\mathbf{F} 28$ sample, the resulting anisotropy constant $K_{\text {eff }}$ is higher than $K_{1}$ probably due to the contribution of the shape anisotropy (should be considered for elongated NPs with the aspect ratio >1.1 [67]), and/or the anisotropy coming from the magneto-dipole interaction of the particles. It is well known that with increasing particle size, the interparticle interactions increases and tend to form aggregates of nanocrystals [70]. Additionally, it seems that the surface anisotropy can be neglected in all three samples due to the diminishing effect of surface spin disordered in cubic-like nanoparticles at low temperatures $[20,70]$. Following the simple analytical approach, the anisotropy properties of Z18 and MZ17 samples seem to be dominated by crystal-field effect $[69,71]$.

It is worth mentioning that the problem with estimation of $K_{\text {eff }}$ still remain opened for nanoparticulate systems. For an ensemble of the magnetic nanoparticles it is difficult to evaluate $K_{\text {eff }}$ due to the fact that apart from the magnetocrystalline, the shape and the surface anisotropies, the anisotropy comes from interparticle interactions and is dependent on the configuration of the particles inside ensembles (i.e. orientation of their easy axis of magnetization relative to the applied magnetic field). When an ensemble of magnetic nanoparticles is subject to an alternating current (AC) magnetic field (as in magnetic hyperthermia application), then the effective anisotropy $K_{\text {eff }}$ can be changed (the magnetization process, as well as the topology of the particles can be changed). Thus, $K_{\text {eff }}$ may obey particular dependence upon the frequency, $f$ and AC field amplitude, $H_{0}$ variations [70, 72, 73]. This fact can significantly change the hyperthermia efficiency of magnetic nanoparticles. Comparing some literature results based on ferromagnetic resonance experiments, we may expect decrease of the $K_{\text {eff }}$ with increasing frequency $f$ [70], as well as with a field amplitude $H_{0}$ increase [72]. Additionally, a significant reduce of the $K_{\text {eff }}$ can be found in in vivo conditions, when IONPs are taken by live cells [14]. With decreasing the $K_{\text {eff }}$ value, a metastable regime of heating can be established in AC magnetic fields.

More realistic description of the $K_{\text {eff }}$ can be obtained from the numerical calculations for multi-particle systems. Another alternative approach is an atomistic spin model [74]. These methods should involve the consideration of the surface spin disorder, the shape anisotropy, the topology of the nanoparticles in an ensemble, the diamagnetic contribution, the Zeeman's 
splitting of atomic energy levels in the magnetic field. A complexity of determining the $K_{\text {eff }}$ values (especially under AC magnetic conditions) are reflected on a heating efficiency study.

\subsection{Heating abilities of pure, $\mathrm{Zn}$ - and (Mn,Zn)-doped samples.}

In figure 6 are shown the heating ability of oleic acid (OA)-coated magnetic Z18, F28 and MZ17 nanoseeds dispersed in hexane, when the nanoparticle were exposed to AC magnetic field of amplitudes, $H_{0}$ in the range between 7 and $23.87 \mathrm{kA} / \mathrm{m}$ and frequency $f=228$ or $252 \mathrm{kHz}$. Some characteristic hyperthermia curves of the samples are given in figure S6. The values of the intensity of magnetic field $H_{0}$ and frequency $f$ are in the range commonly used in the literature $[6,20,21,65]$, even though their product, $H_{0} \times f$ (between $1.6 \times 10^{9}$ and $6.0 \times 10^{9} \mathrm{Am}^{-1} \mathrm{~s}^{-1}$ ), exceeds the value limited by the Atkinson-Brezovich criterion $\left(4.85 \times 10^{8} \mathrm{Am}^{-1} \mathrm{~s}^{-1}\right)$ [75], for one order of magnitude. If we assume that the magnetic/hyperthermia treatment will be applied locally (for tissue heating), the use of larger field-frequency product may be considered tolerable for the human body [76].

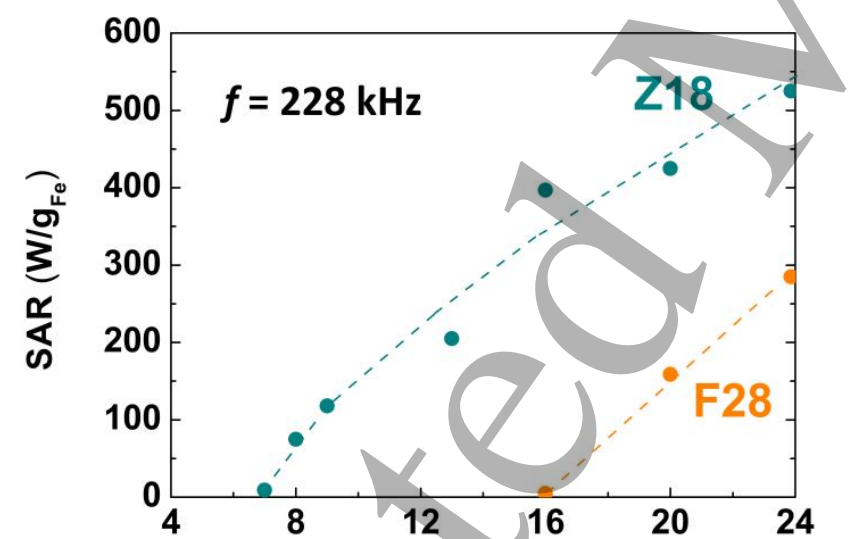

(a)

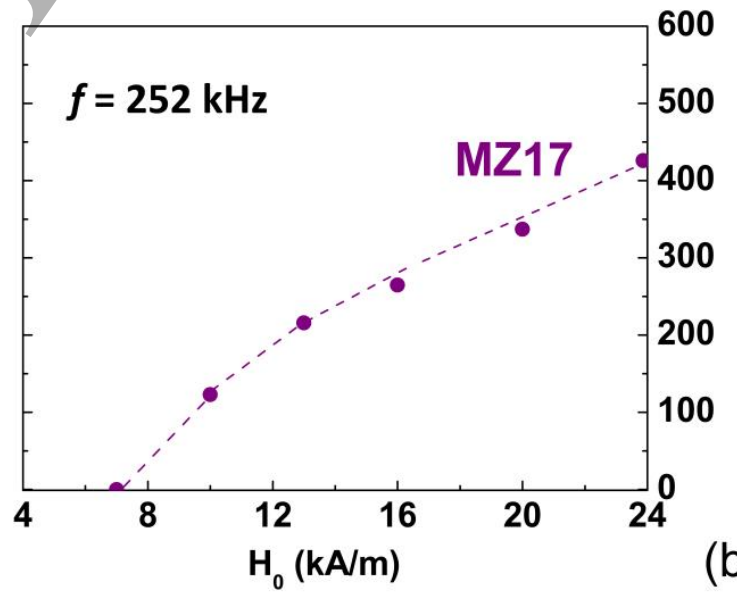

Figure 6. The $S A R$ values of samples (a) Z18 and F28 and (b) MZ17 measured at frequency $f$, for different applied magnetic fields. Dash-line is a guide for eyes.

As we can see from figure 6, the increase of $S A R$ value upon field amplitude is observed for higher $H_{0}$ values in all three samples, with the difference in the offset of the heating for substituted and unsubstituted samples. Substituted samples, Z18 and MZ17, start to release heat 
before the F28 ferrofluid (i.e. F28 nanoseeds needs higher amplitude of the applied field, $H_{0}$, to start to generate heat). The estimated $S A R$ values of three samples seems to be correlated with the field cooled (FC) magnetization value, $M_{\mathrm{FC}}$, measured in a low field of $7.96 \mathrm{kA} / \mathrm{m}$ (100 Oe), as well as the saturation magnetization to coercivity ratio, $M_{\mathrm{S}} / H_{\mathrm{C}}$, at $5 \mathrm{~K}$. The unsubstituted magnetite nanoparticles, F28, have the lowest $\mathrm{M}_{\mathrm{FC}}$ and $M_{\mathrm{S}} / H_{\mathrm{C}}$ values and consequently lower heating potential under the same experimental conditions $\left(H_{0} f\right)$, in comparison with $\mathbf{Z 1 8}$ and MZ17. This can be partially due to the broader particle size distribution in F28 (bigger NPs, which stay blocked and do not participate in the transformation of magnetic to thermal energy), as well as to the formation of nanoclusters. The relaxation time for nanoclusters and single nanoparaticles can differ [77], consequently bringing the changes in the heating abilities (i.e. $S A R$ values). In addition, the lower intrinsic loss parameters value, ILP $\left(I L P=S A R /\left(H_{0}^{2} f\right)\right)$, could also indicate on the formation of nanoclusters in the sample F28 (see table 4). Zincsubstituted $\mathrm{Fe}_{3} \mathrm{O}_{4}$ cubo-octahedrons, $\mathbf{Z 1 8}$, show the best heating performances. This sample has a good potential for using in the hyperthermia therapy. On inspection of literature, we just mention some $S A R$ and ILP values of nanoparticles similar in size, composition and shape with here studied ones. Thus, $18 \mathrm{~nm}$-sized $\mathrm{Zn}_{0.4} \mathrm{Fe}_{2.6} \mathrm{O}_{4}$ cubes have shown $S A R=1860 \mathrm{~W} / \mathrm{g}$ at $H_{0}=37.4$ $\mathrm{kA} / \mathrm{m}$ and $f=500 \mathrm{kHz}(I L P=2.66 \mathrm{nH} \mathrm{m} / \mathrm{kg})$ [20], while $15.4 \mathrm{~nm}$-sized $\mathrm{Zn}_{0.4} \mathrm{Fe}_{2.6} \mathrm{O}_{4}$ cubes possess higher heating potential, i.e. $S A R=1019.2 \mathrm{~W} / \mathrm{g}$ at $H_{0}=16 \mathrm{kA} / \mathrm{m}$ and $f=380 \mathrm{kHz}$, and $I L P$ $=10.5 \mathrm{nH} \mathrm{m}^{2} / \mathrm{kg}$ [6]. On the other hand, $17 \mathrm{~nm}$ - and 26nm-sized octopods of composition FeO$\mathrm{Fe}_{3} \mathrm{O}_{4}$ have $S A R$ and $I L P$ values of $\sim 190$ and $150 \mathrm{~W} / \mathrm{g}$ and 1 and $0.8 \mathrm{nH} \mathrm{m} / \mathrm{kg}$, respectively, when are exposed to $\mathrm{AC}$ field of $H_{0}=24.67 \mathrm{kA} / \mathrm{m}$ and $f=310 \mathrm{kHz}$ [65]. Bigger iron oxide nanocubes, with an average size $\sim 23 \mathrm{~nm}$ have $S A R=375 \mathrm{~W} / \mathrm{g}_{\mathrm{Fe}}$ at $H_{0}=24 \mathrm{kA} / \mathrm{m}$ and $f=301 \mathrm{kHz}$ [21], and very similar ILP value $\left(2.16 \mathrm{nH} \mathrm{m}^{2} / \mathrm{kg}\right)$, as our $\mathbf{F 2 8}$ nanoparticles. To what extent the heating ability of our nanoparticles will be influenced by the media viscosity, clustering and interparticle interactions will be a task for our future investigations.

\section{Conclusion}

The single crystalline $\mathrm{Fe}_{3} \mathrm{O}_{4}$-based nanoparticles, pure or substituted by zinc or (zinc, manganese) of size above $15 \mathrm{~nm}$ were fabricated by a thermal decomposition of metal precursors. The incorporation of $\mathrm{Zn}^{2+}$ ions into a spinel structure was found to be difficult, even 
though two different sources of $\mathrm{Zn}^{2+}$ ions were used, $\mathrm{Zn}(\mathrm{acac})_{2}$ and $\mathrm{ZnCl}_{2}$ salt. The XRD analysis revealed presence of the pure magnetite-based phase in all three samples. In terms of crystallinity and size dispersion, this synthesis protocol shows superiority over decomposition of iron oleate and the co-precipitation synthesis route. High saturation magnetization and single magnetic phase were detected in all three samples. Slightly cation-deficient magnetite phase could only be presented at the nanoparticle's surface, but is negligible for magnetization diminution. $18 \mathrm{~nm}$-sized $\mathrm{Zn}_{0.13} \mathrm{Fe}_{2.87} \mathrm{O}_{4}$ cuboctahedrons, with the specific absorption rate, $S A R \cong$ $425 \mathrm{~W} / \mathrm{g}_{\mathrm{Fe}}$ at $H_{0}=20 \mathrm{kA} / \mathrm{m}$ and $f=228 \mathrm{kHz}$, show the best heating performance.

\section{Acknowledgments}

The article is based upon work from COST Action RADIOMAG (TD1402), supported by COST (European Cooperation in Science and Technology). N.J.O. gives special thanks to Prof. Gerardo F. Goya of University of Zaragoza for his support to get STSM grant and for providing work facilities at the Institute of Nanoscience of Aragón. N.J.O. and M.M.M. acknowledge the Ministry of Education, Science and Technological Development of the Serbian Republic for financial support through the projects No. 45015 and 171027. T.E.T. acknowledge financial support from the Spanish Ministerio de Economia y Competitividad (MINECO) through project MAT2016-78201-P and by the Aragón Regional Government (DGA), through the Research Groups grants (E-26 and E28-17R) co-financed by the FEDER Operational Program Aragón 2014ï 2020 ñBuilding Europe from Aragonò. We are grateful to the Advanced Microscopy Laboratory (LMA) and the SAI-UZ for technical assistance. We thank Dr. V. Spasojevil for the magnetometer measurements, Dr. V. Ivanoski and Dr. A. Umil evil for the Mössbauer spectra collecting, Prof. N. Cvjetil anin for TGA/DTA data collecting and Prof. A. Kremenovil for critical reading of the text.

\section{REFERENCES}

[1] $\mathrm{Xu} \mathrm{C}$ and Sun S $2013 \mathrm{New}$ forms of superparamagnetic nanoparticles for biomedical applications Adv. Drug Delivery Rev. 65 732-43

[2] Torres-Lugo M and Rinaldi C 2013 Thermal potentiation of chemotherapy by magnetic nanoparticles Nanomedicine 8(10) 1689111707 
[3] Zhu Y -F, Ni Q -Q, Fu Y -Q and Natsuki T 2013 Synthesis and microwave absorption properties of electromagnetic functionalized $\mathrm{Fe}_{3} \mathrm{O}_{4} \mathrm{I}$ polyaniline hollow sphere nanocomposites produced by electrostatic self-assembly J. Nanopart. Res. 151988

[4] Zhang J and Yu A 2015 Nanostructured transition metal oxides as advanced anodes for lithium-ion batteries Sci. Bull. 60(9) 823 Ï 38

[5] Jang J -t, Nah H, Lee J -H, Moon S H, Kim M G and Cheon J 2009 Critical Enháncements of MRI Contrast and Hyperthermic Effects by Dopant-Controlled Magnetic Nanoparticles Angew. Chem. Inter. Ed. 48 1234-38

[6] Bauer L M, Situ S F, Griswold M A and Samia A C S 2016 High-performance iron oxide nanoparticles for magnetic particle imaging ï guided hyperthermia (hMPI) Nanoscale 812162 [7] Goya G F, Grazu V and Ibarra M R 2008 Magnetic Nanoparticles for Cancer Therapy Curr. Nanosci. 4 1-16

[8] Starsich F H L, Eberhardt C, Boss A, Hirt A M and Pratsinis S E 2018 Coercivity Determines Magnetic Particle Heating Adv. Helathcare Mater. 1800287

[9] Tong S, Quinto C A, Zhang L, Mohindra P and Bao G 2017 Size-Dependent Heating of Magnetic Iron Oxide Nanoparticles ACS Nano 11 6808-16

[10] Iacovita C, Florea A, Dudric R, Pall E, Iulian Moldovan A, Tetean R, Stiufiuc R and Lucaciu C M 2016 Small versus Large Iron Oxide Magnetic Nanoparticles: Hyperthermia and Cell Uptake Properties Molecules 211357

[11] Xie W, Guo Z, Gao F, Gao Q, Wang D, Liaw B-s, Cai Q, Sun X, Wang X and Zhao L 2018 Shape-, size- and structure-controlled synthesis and biocompatibility of iron oxide nanoparticles for magnetic theranostics Theranostic 8 3284-307

[12] Noh S -H, Ho Moon S, Shin T-H, Lim Y and Cheon J 2017 Recent advances of magnetothermal capabilities of nanoparticles: From design principles to biomedical applications Nano Today 13 61-76

[13] Hao R, Xing R, Xu Z, Hou Y, Gao S and Sun S 2010 Synthesis, Functionalization, and Biomedical Applications of Multifunctional Magnetic Nanoparticles Adv. Mater. $222729 \ddot{~} 42$ [14] Cabrera D, Coene A, Leliaert J, Artés-Ibáñez E J, Dupré L, Telling N D and Teran F J 2018 Dynamical Magnetic Response of Iron Oxide Nanoparticles Inside Live Cells ACS Nano 12 $2741-52$ 
[15] Das R, Alonso J, Nemati Porshokouh Z, Kalappattil V, Torres D, Phan M -H, Garaio E, Ángel García J, Sanchez Llamazares J Land Srikanth H 2016 Tunable High Aspect Ratio Iron Oxide Nanorods for Enhanced Hyperthermia J. Phys. Chem. C 120 10086-93

[16] Moya C, Batlle X and Labarta A 2015 The effect of oleic acid on the synthesis of $\mathrm{Fe}_{3-\mathrm{x}} \mathrm{O}_{4}$ nanoparticles over a wide size range Phys. Chem. Chem. Phys. 17 27373-79

[17] Bárcena C, Sra A K, Chaubey G S, Khemtong C, Ping Liu J and Gao J 2008 Zinc ferrite nanoparticles as MRI contrast agents Chem. Comm. 2224-26

[18] Yang Y, Liu X, Yang Y, Xiao W, Li Z, Xue D, Li F and Ding J 2013 Synthesis of nonstoichiometric zinc ferrite nanoparticles with extraordinary room temperature magnetism and their diverse applications J. Mater. Chem. C 1 2875-85

[19] Kolhatkar A G, Chen Y -T, Chinwangso P, Nekrashevich I, Dannangoda G C, Singh A, Jamison A C, Zenasni O, Rusakova I A, Martirosyan K S, Litvinov D, Xu S, Willson R C and Randall Lee T 2017 Magnetic Sensing Potential of $\mathrm{Fe}_{3} \mathrm{O}_{4}$ Nanocubes Exceeds That of $\mathrm{Fe}_{3} \mathrm{O}_{4}$ Nanospheres ACS Omega 2 8010-19

[20] Noh S -H, Na W, Jang J -t, Lee J -H, Jung Lee E, Ho Moon S, Lim Y, Shin J -S and Cheon J 2012 Nanoscale Magnetism Control via Surface and Exchange Anisotropy for Optimized Ferrimagnetic Hysteresis Nano Lett. 12 3716-21

[21] Lak A, Cassani M, Mai B T, Winckelmans N, Cabrera D, Sadrollahi E, Marras S, Remmer H, Fiorito S, Cremades-Jimeno L, Jochen Litterst F, Ludwig F, Manna L, Teran F J, Bals S and Pellegrino T $2018 \mathrm{Fe}^{2+}$ Deficiencies, FeO Subdomains, and Structural Defects Favor Magnetic Hyperthermia Performance of Iron Oxide Nanocubes into Intracellular Environment Nano Lett. $186856 і ̈ 66$

[22] Mendoza Zélis P, Pasquevich G A, Stewart S J, Fernández van Raap M B, Aphesteguy J, Bruvera I J, Laborde C, Pianciola B, Jacobo S, Sánchez F H, Structural and magnetic study of zinc-doped magnetite nanoparticles and ferrofluids for hyperthermia applications $2013 \mathrm{~J}$. Phys. D: Appl. Phys. 46125006

[23] Andrés Vergés M, Costo R, Roca A G, Marco J F, Goza G F, Serna C J and Morales M P 2008 Uniform and water stable magnetite nanoparticles with diameters around the monodomainï multidomain limit J. Phys. D: Appl. Phys. 41134003 
[24] Pacakova B, Kubickova S, Salas G, Mantlikova A, Marciello M, Morales M P, Niznansky D and Vejpravova J 2017 Internal structure of magnetic nanoparticle determines magnetic response Nanoscale $\mathbf{9}$ 5129-40

[25] Ichikawa R U, Roca A G, López-Ortega A, Estrader M, Peral I, Turrillas X and Nogués J 2018 Combining X-Ray Whole Powder Pattern Modeling, Rietveld and Pair Distribution Function Analyses as a Novel Bulk Approach to Study Interfaces in Heteronanostructures: Oxidation Front in $\mathrm{FeO} / \mathrm{Fe}_{3} \mathrm{O}_{4}$ Core/Shell Nanoparticles as a Case Study Small 14 e1800804 [26] Joviĺ Orsini N, Babiĺ-Stojiĺ B, Spasojeviĺ V, Calatayud M P, Cvjetil anin N and Goya G F 2018 Magnetic and power absorption measurements on iron oxide nanoparticles synthesized by thermal decomposition of Fe(acac) $)_{3}$ J. Magn. Magn. Mater. 449 286-96

[27] Bonsdorf G, Denecke M A, Schäfer K, Christen S, Langbein H and Gunßer W 1997 X-ray absorption spectroscopic and Mössbauer studies of redox and cation-ordering processes in manganese ferrite Solid State Ion. 101-103 351-57

[28] Rodríguez-Carvajal J 2001 Recent developments of the program FULLPROF IUCr Commission on powder diffraction Newsletter 26 12-19

[29] Stephens P W 1999 Phenomenological model of anisotropic peak broadening in powder diffraction J. Appl. Phys. 32 281-89

[30] Cheon J -W, Seo J -W and Lee J -H 2006 Preparation method of magnetic and metal oxide nanoparticles, Korean PATENT PCT $\quad$ WO $2006 / 052042 \quad$ A1 (https://www.google.com/patents/WO2006052042A1)

[31] Lak A, Kraken M, Ludwig F, Kornowski A, Eberbeck D, Sievers S, Litterst F J, Weller H

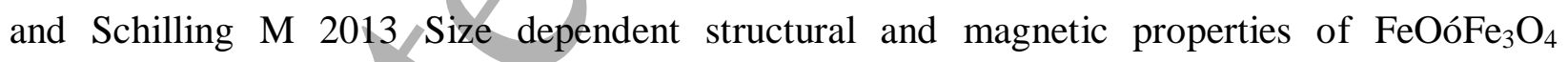
nanoparticles Nanoscale 5 12286-95

[32] Shavel A, Rodríguez-González B, Pacifico J, Spasova M, Farle M and Liz-Marzán L M 2009 Shape Control in Iron Oxide Nanocrystal Synthesis, Induced by Trioctylammonium Ions Chem. Mater. 21 1326-32

[33] Yang H, Ogawa T, Hasegawa D and Takahash M 2008 Synthesis and magnetic properties of monodisperse magnetite nanocubes J. Appl. Phys. 103 07D526

[34] Liang W -I, Zhang X, Bustillo K, Chiu C -H, Wu W -W, Xu J, Chu Y -H and Zheng H 2015 In Situ Study of Spinel Ferrite Nanocrystal Growth Using Liquid Cell Transmission Electron Microscopy Chem. Mater. 27 8146-52 
[35] Baird N, Losovyj Y, Yuzik-Klimova E Yu, Kuchkina N V, Shifrina Z B, Pink M, Stein B D, Morgan D G, Wang T, Rubin M A, Sidorov A I, Sulman E M and Bronstein L M 2016 ZincContaining Magnetic Oxides Stabilized by a Polymer: One Phase or Two? ACS Appl. Mater. Interfaces $\mathbf{8} 891$ ī 99

[36] https://www.ill.eu/sites/fullprof/php/tutorials.html

[37] Gorski C A and Scherer M M 2010 Determination of nanoparticulate magnetite stoichiometry by Mössbauer spectroscopy, acidic dissolution, and powder X-ray diffraction: A critical review Am. Mineral. 951017 ï 26

[38] Woo K, Hong J, Choi S, Lee H -W, Ahn J -P, Kim C S and Lee S W 2004 Easy Synthesis and Magnetic Properties of Iron Oxide Nanoparticles Chem. Mater. 16 2814-18

[39] Dézsi I, Fetzer Cs, GombkötṚ Á, SzŤcs I, Gubicza J and Ungár T 2008 Phase transition in nanomagnetite J. Appl. Phys. 103104312

[40] Annersten H and Hafner S S 1973 Vacancy distribution in synthetic spinels of the series $\mathrm{Fe}_{3} \mathrm{O}_{4}-\gamma-\mathrm{Fe}_{2} \mathrm{O}_{3}$ Z. Kristallogr. $137321-40$

[41] Schmidbauer E and Keller M 2006 Magnetic hysteresis properties, Mössbauer spectra and structural data of spherical $250 \mathrm{~nm}$ particles of solid solutions $\mathrm{Fe} 3 \mathrm{O} 4$ ï ว-Fe2 $\mathrm{O}_{3}$ J. Magn. Magn. Mater. 297 107-17

[42] Lima Jr E, Brandl A L, Arelaro A D and G. F. Goya 2006 Spin disorder and magnetic anisotropy in $\mathrm{Fe}_{3} \mathrm{O}_{4}$ nanoparticles J. Appl. Phys. 99083908

[43] da Costa G M, Blanco-Andujar C, De Grave E and Pankhurst Q A 2014 Magnetic nanoparticles for in vivo use: A critical assessment of their composition J. Phys. Chem. B 118 11738-46

[44] Ramdani A, Steinmetz J, Gleitzer C, Coey J M D and Friedt J M 1987 Perturbation de l'echange electronique rapide par les lacunes cationiques dans $\mathrm{Fe}_{3 \bar{x}} \mathrm{O}_{4}(\mathrm{x} \leqslant 0,09)$ J. Phys. Chem. Solids 48 217-28

[45] Yang J B, Zhou X D, Yelon W B, James W J, Cai Q, Gopalakrishnan K V, Malik S K, Sun X C and Nikles D E 2004 Magnetic and structural studies of the Verwey transition in $\mathrm{Fe}_{3 \bar{i}} \mathrm{u}_{4}$ nanoparticles J. Appl. Phys. 95 7540-42

[46] Santoyo Salazar J, Perez L, de Abril O, Truong Phuoc L, Ihiawakrim D, Vazquez M, Greneche J M, Begin-Colin, S and Pourroy G 2011 Magnetic iron oxide nanoparticles in 10̄̄ 40 
$\mathrm{nm}$ range: composition in terms of magnetite/maghemite ratio and effect on the magnetic properties Chem. Mater. 23 1379-86

[47] Daou T J, Pourroy G, Bégin-Colin S, Greneche J M, Ulhaq-Bouillet C, Legaré P, Bernhardt P, Leuvrey C and Rogez G 2006 Hydrothermal synthesis of monodisperse magnetite nanoparticles Chem. Mater. 18 4399-404

[48] Wen M, Li Q and Li Y 2006 Magnetic, electronic and structural properties of $\mathrm{Zn}_{x} \mathrm{Fe}_{3-\mathrm{x}} \mathrm{O}_{4} J$. Electron Spectros. Relat. Phenomena 153 65-70

[49] Handke B, Haber J, ślňzak T, Kubik M and Korecki J 2001 Magnesium interdiffusion and surface oxidation in magnetite epitaxial films grown on $\mathrm{MgO}$ (100) Vacuum 63 331-36

[50] Olivier L C A, Fabris J D, Rios R R V A, Mussel W N and Lago R M $2004 \mathrm{Fe}_{3 \bar{x}} \mathrm{Mnn}_{\mathrm{x}} \mathrm{O}_{4}$ catalysts: phase transformations and carbon monoxide oxidation Appl. Catal. A Gen. 259 253-59 [51] Antic B, Kremenovic A, Jovic N, Pavlovic M B, Jovalekic C, Nikolic A S, Goya G F and Weidenthaler C 2012 Magnetization enhancement and cation valences in nonstoichiometric

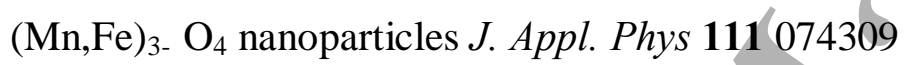

[52] Lotgering F K and Van Diepen A M 1973 Valencies of manganese and iron ions in cubic ferrites as observed in paramagnetic Mössbauer spectra J. Phys. Chem. Solids 34 1369-77

[53] Di Corato R, Aloisi A, Rella S, Grenèche J -M, Pugliese G, Pellegrino T, Malitesta C O and Rinaldi R 2018 Maghemite Nanoparticles with Enhanced Magnetic Properties: One Pot Preparation and Ultrastable Dextran Shell ACS Appl. Mater. Interfaces 10 20271̄i 80

[54] Sorescu M, Diamandescu L, Brand R A and Tarabasanu-Mihaila D 2004 Mössbauer study of manganese-doped magnetite below the Verwey transition Mater. Lett. 58 885-88

[55] Greenwood N N and Gibb T C 1971 in Mössbauer Spectroscopy (London: Chapman and Hall Ltd) p 241

[56] Martinez B, Roig A, Obrados X, Molins E, Rouanet A and Monty C 1996 J. Appl. Phys. 79 2580-86

[57] Fock J, Bogart L K, González-Alonso D, Espeso J I, Hansen M F, Varón M, Frandsen C, Pankhurst Q A J. Phys. D: Appl. Phys. 50265005

[58] Palmer W 1963 Magnetocrystalline anisotropy of magnetite at low temperature Phys. Rev. 131 1057-62 
[59] Koğdziej T, Kozø̆wski A, Piekarz P, TabiŜW, KŃkol Z, ZajŃł M, Tarnawski Z, Honig J M, OleŜA M and Parlinski K 2012 Nuclear inelastic scattering studies of lattice dynamics in magnetite with a first-and second-order Verwey transition Phys. Rev. B 85104301

[60] Aragón R, Buttrey D J, Shepherd J P and Honig J M 1985 Influence of nonstoichiometry on the Verwey transition Phys. Rev. B 31 430-36

[61] Özdemir O, Dunlop D J and Moskowitz B M 1993 The effect of oxidation on the Verwey transition in magnetite Geophys. Res. Lett. 20 1671-74

[62] Daou T J, Grenèche J M, Pourroy G, Buathong S, Derory A, Ulhaq-Bouillet C, Donnio B, Guillon D and Begin-Colin S 2008 Coupling Agent Effect on Magnetic Properties of Functionalized Magnetite-Based Nanoparticles Chem. Mater, $205869 i$

[63] Nedelkoski Z, Kepaptsoglou D, Lari L, Wen T, Booth R A, Oberdick S D, Galindo P L, Ramasse Q M, Evans R F L, Majetich S and Lazarov V/ K 2017 Origin of reduced magnetization and domain formation in small magnetite nanoparticles Sci. Rep. 745997

[64] Stoner E C and Wohlfarth E P 1948 A mechanism of magnetic hysteresis in heterogeneous alloys Phil. Trans. R. Soc. A240 599ї 642

[65] Nemati Z, Alonso J, Martinez L M, Khurshid H, Garaio E, Garcia J A, Phan M H and Srikanth H 2016 Enhanced Magnetic Hyperthermia in Iron Oxide Nano-Octopods: Size and Anisotropy Effects J. Phys. Chem. C 120 8370̄79

[66] Mulea A, Muñoz D, Martín-Rodríguez R, Orue I, Garaio E, Abad Díaz de Cerio A, Alonso J, Ángel García J, Luisa Fdez-Gubieda M 2016 Optimal Parameters for Hyperthermia Treatment Using Biomineralized Magnetite Nanoparticles: Theoretical and Experimental Approach J. Phys. Chem. C 120 24437-48

[67] Usov N A and Barandiaran J M 2012 Magnetic nanoparticles with combined anisotropy $J$. Appl. Phys. 112053915

[68] Schmitz D, Schmitz-Antoniak C, Warland A, Darbandi M, Haldar S, Bhandary S, Eriksson O, Sanyal B and Wende H 2014 The dipole moment of the spin density as a local indicator for phase transitions Sci. Rep. 45760

[69] ř ezníl ek R, Chlan V, Ġ̣pánková H, Novák P and Maryg̉ko M 2012 Magnetocrystalline anisotropy of magnetite J. Phys.: Condens. Matter 24055501 
[70] Charilaou M, Sahu K K, Faivre D, Fischer A, García-Rubio I and Gehring A U 2011 Evolution of magnetic anisotropy and thermal stability during nanocrystal-chain growth Appl. Phys. Lett. 99182504

[71] K带l Z and Honig J M 1989 Influence of deviations from ideal stoichiometry on the anisotropy parameters of magnetite $\mathrm{Fe}_{3(11 \mathrm{i})} \mathrm{O}_{4}$ Phys. Rev. B 409090

[72] Ivanov A O, Kantorovich S S, Zverev V S, Elfimova E A, Lebedev A V and Pśhenichnikov A F 2016 Temperature-dependent dynamic correlations in suspensions of magnetic nanoparticles in a broad range of concentrations: a combined experimental and theoretical study Phys. Chem. Chem. Phys. 18 18342-52

[73] Usov N A 2010 Low frequency hysteresis loops of superparamagnetic nanoparticles with uniaxial anisotropy J. Appl. Phys. 107123909

[74] Moreno R, Poyser S, Meilak D, Meo A, Jenkins S, Lazarov V K, Vallejo-Fernandez G, Majetich S and Evans R F L 2019 The role of faceting and elongation on the magnetic anisotropy of magnetite $\mathrm{Fe}_{3} \mathrm{O}_{4}$ nanocrystals arXiv: $1909.02470 \mathrm{v} 1$

[75] Atkinson W J, Brezovich I A and Chakraborty D P 1984 Usable Frequencies in Hyperthermia with Thermal Seeds IEEE Trans. Biomed. Eng. 3170 ï 5

[76] Hergt R and Dutz S 2007 Magnetic particle hyperthermia-biophysical limitations of a visionary tumour therapy J. Magn. Magn. Mater. $311187 i ̈ 192$

[77] Wu K and Wang J P 2017 Magnetic hyperthermia performance of magnetite nanoparticle assemblies under different driving fields AIP Advances 7056327 